\title{
Jet characterization in the upper troposphere/lower stratosphere (UTLS): applications to climatology and transport studies
}

\author{
G. L. Manney ${ }^{1,2}$, M. I. Hegglin ${ }^{3}$, W. H. Daffer ${ }^{1}$, M. L. Santee ${ }^{1}$, E. A. Ray $^{4,5}$, S. Pawson ${ }^{6}$, M. J. Schwartz ${ }^{1}$, \\ C. D. Boone ${ }^{7}$, L. Froidevaux ${ }^{1}$, N. J. Livesey ${ }^{1}$, W. G. Read $^{1}$, and K. A. Walker ${ }^{3,7}$ \\ ${ }^{1}$ Jet Propulsion Laboratory, California Institute of Technology, Pasadena, CA, USA \\ ${ }^{2}$ New Mexico Institute of Mining and Technology, Socorro, NM, USA \\ ${ }^{3}$ University of Toronto, Toronto, Ontario, Canada \\ ${ }^{4}$ Cooperative Institute for Research in Environmental Sciences, University of Colorado, Boulder, CO, USA \\ ${ }^{5}$ Earth Systems Research Laboratory, NOAA, Boulder, CO, USA \\ ${ }^{6}$ NASA/Goddard Space Flight Center, Greenbelt, MD, USA \\ ${ }^{7}$ University of Waterloo, Waterloo, Ontario, Canada
}

Received: 21 December 2010 - Published in Atmos. Chem. Phys. Discuss.: 19 January 2011

Revised: 19 May 2011 - Accepted: 16 June 2011 - Published: 29 June 2011

\begin{abstract}
A method of classifying the upper tropospheric/lower stratospheric (UTLS) jets has been developed that allows satellite and aircraft trace gas data and meteorological fields to be efficiently mapped in a jet coordinate view. A detailed characterization of multiple tropopauses accompanies the jet characterization. Jet climatologies show the well-known high altitude subtropical and lower altitude polar jets in the upper troposphere, as well as a pattern of concentric polar and subtropical jets in the Southern Hemisphere, and shifts of the primary jet to high latitudes associated with blocking ridges in Northern Hemisphere winter. The jet-coordinate view segregates air masses differently than the commonly-used equivalent latitude (EqL) coordinate throughout the lowermost stratosphere and in the upper troposphere. Mapping $\mathrm{O}_{3}$ data from the Aura Microwave Limb Sounder (MLS) satellite and the Winter Storms aircraft datasets in jet coordinates thus emphasizes different aspects of the circulation compared to an EqL-coordinate framework: the jet coordinate reorders the data geometrically, thus highlighting the strong PV, tropopause height and trace gas gradients across the subtropical jet, whereas EqL is a dynamical coordinate that may blur these spatial relationships but provides information on irreversible transport. The jet coordinate view identifies the concentration of stratospheric ozone well below the tropopause in the region poleward of and below the jet core, as well as other transport features associated with the upper tropospheric jets. Using the jet information in EqL coordinates allows us to study trace
\end{abstract}

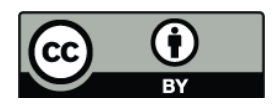

Correspondence to: G. L. Manney (gloria.1.manney@jpl.nasa.gov) gas distributions in regions of weak versus strong jets, and demonstrates weaker transport barriers in regions with less jet influence. MLS and Atmospheric Chemistry ExperimentFourier Transform Spectrometer trace gas fields for spring 2008 in jet coordinates show very strong, closely correlated, $\mathrm{PV}$, tropopause height and trace gas gradients across the jet, and evidence of intrusions of stratospheric air below the tropopause below and poleward of the subtropical jet; these features are consistent between instruments and among multiple trace gases. Our characterization of the jets is facilitating studies that will improve our understanding of upper tropospheric trace gas evolution.

\section{Introduction}

The upper tropospheric jets and the lowest part of the stratospheric polar night jet (referred to hereinafter as the subvortex jet) are dominant influences in determining many characteristics of upper tropospheric/lower stratospheric (UTLS) circulation and transport. Evolution of and trends in the jets themselves potentially reflect and propagate effects of climate change. Several studies suggest that a widening of the "tropical belt", i.e., a poleward shift of the subtropical jet, is expected in a changing climate (Lorenz and DeWeaver, 2007; Seidel et al., 2008, and references therein), and recent studies provide observational evidence of such changes (e.g., Strong and Davis, 2007, 2008a; Archer and Caldeira, 2008). Climate model studies suggest that the upper tropospheric and subvortex jets control the circulation response to greenhouse-gas induced tropospheric warming through their

Published by Copernicus Publications on behalf of the European Geosciences Union. 
effect on wave drag (McLandress and Shepherd, 2009; Sigmond and Scinocca, 2010), and that the Southern Hemisphere ( $\mathrm{SH}$ ) jets exhibit strong sensitivity to ozone depletion and recovery (e.g., Son et al., 2008).

In addition to the UTLS jets responding to and providing diagnostics of climate change, they are the dominant feature organizing transport in the UTLS and are instrumental in controlling extra-tropical stratosphere/troposphere exchange (STE). The chemical composition of the UTLS, particularly ozone $\left(\mathrm{O}_{3}\right)$ and water vapor $\left(\mathrm{H}_{2} \mathrm{O}\right)$, is critically important in that radiative forcing of surface temperatures is most sensitive to $\mathrm{O}_{3}$ and $\mathrm{H}_{2} \mathrm{O}$ changes near the tropopause (e.g., Lacis et al., 1990; Forster and Shine, 1997; Solomon et al., 2010). In addition, the Antarctic $\mathrm{O}_{3}$ hole has caused significant lower stratospheric temperature change (Shine et al., 2003). Although $\mathrm{O}_{3}$ depletion occurs throughout the lower stratosphere, a substantial portion of that depletion takes place in the subvortex, the lowest part of the polar vortex that extends into the lowermost stratosphere (the region of the stratosphere between the tropical tropopause level, typically $380 \mathrm{~K}$ potential temperature, and the extratropical tropopause, e.g., Holton et al., 1995). At these altitudes, ozone-depleted air can be more efficiently transported to midlatitudes (e.g., Lee et al., 2002; Santee et al., 2011) because the permeability of the transport barriers defined by the UTLS jets is greater than that in the vortex proper.

Changes in the Brewer-Dobson Circulation and in synoptic eddies in the upper troposphere are expected to alter both the structure and evolution of the jets (e.g., Butchart and Scaife, 2001; Shepherd, 2008) and the extent and consequences of extratropical STE (e.g., Hegglin and Shepherd, 2009). Pollution products transported up into the lower stratosphere influence $\mathrm{O}_{3}$ chemistry (e.g. Hegglin et al., 2006; Levine et al., 2007; Duncan et al., 2007; World Meteorological Organization, 2007); stratospheric $\mathrm{O}_{3}$ transported down into the upper troposphere also influences tropospheric chemistry (e.g., World Meteorological Organization, 2007; Ordóñez et al., 2007; Terao et al., 2008; Hsu and Prather, 2009); this two-way exchange is organized and its characteristics are in large part determined by the UTLS jets. An important factor influencing extratropical STE, especially quasi-isentropic transport and mixing, is Rossby-wave breaking, which has been shown to be prevalent along the flanks of the upper tropospheric jets and subvortex jet (e.g., Randel and Held, 1991; Hitchman and Huesmann, 2007; Isotta et al., 2008). Hegglin et al. (2009) showed evidence that the depth of the extratropical transition layer (ExTL, the region with mixed tropospheric and stratospheric characteristics around the extratropical tropopause) is sensitive to patterns of Rossby-wave breaking.

Variations in the tropopause, especially the "tropopause break" across the subtropical jet, are closely linked to upper tropospheric jet structure and evolution, hence detailed information on the tropopause is also critical to understanding the roles of the jets in UTLS dynamics and transport. The most commonly used definitions for determining the vertical position of the tropopause are a "dynamical" definition using potential vorticity (PV) contours in the extra-tropics and a "thermal" definition based on the WMO (World Meteorological Organization) criteria using changes in the temperature gradient (e.g., Holton et al., 1995). As described in detail by Randel et al. (2007b) (also see references therein), double thermal tropopauses are common, and appear to have a relationship to transport and the ExTL, though details of this relationship have yet to be explored.

Several previous studies have presented schemes for automating identification of the upper tropospheric jets (e.g., Koch et al., 2006; Strong and Davis, 2007, 2008a; Archer and Caldeira, 2008; Schiemann et al., 2009). Koch et al. (2006) define the jets over a vertical region from 400 to $100 \mathrm{hPa}$, and use their characterization to develop a two-dimensional (2-D) climatology of upper tropospheric jets. The method of Archer and Caldeira (2008), developed for assessing longterm average trends, defines monthly-mean mass-weighted average wind speeds and pressures for the upper tropospheric jets. As noted by Strong and Davis (2007, 2008a,b), methods such as those of Koch et al. (2006) and Archer and Caldeira (2008) reduce or eliminate information on the vertical structure of the upper tropospheric jets by averaging in the vertical. Schiemann et al. (2009) avoided this simplification by extending the method of Koch et al. (2006) to a threedimensional (3-D) framework to examine seasonal variability of jets in the Tibetan Plateau region. Strong and Davis $(2007,2008$ a) retain more vertical jet structure information, characterizing the jets on the surface defined by the maximum windspeed at each horizontal location. Because of the central importance of the UTLS jets to dynamics and transport on time scales from sub-daily (for study of individual events) to multi-decadal (e.g., climate-change-related trends), we have built upon these studies to develop a technique that is not only appropriate for analyzing the jets on single-event through climatological time scales, but also is useful as a framework for studying 3-D trace gas distributions in relation to the jets on the same wide range of time scales.

Figure 1 provides an example of the complexity of upper tropospheric jet structure in relation to the $\mathrm{O}_{3}$ distribution. At $350 \mathrm{~K}$, near the typical level of the jet core, the tropopause and strong $\mathrm{O}_{3}$ gradients across it tend to follow the meanderings of the "subtropical jet", that is, the low to mid-latitude jet, typically the most equatorward jet, across which the tropopause altitude changes abruptly. However, in the example shown for $370 \mathrm{~K}$ there are regions where the jet is coincident with the tropopause and associated sharp $\mathrm{O}_{3}$ gradients, but other regions where the jet follows a band of strong PV gradients associated with the subvortex jet (these lie along the single representative PV contour shown in magenta). In these regions, the $\mathrm{O}_{3}$ field suggests mixing in a broad area between edge of the subvortex and the tropopause. At both levels, the jet is often discontinuous or may have 
MLS v03.3 370.00K Ozone, 20061115

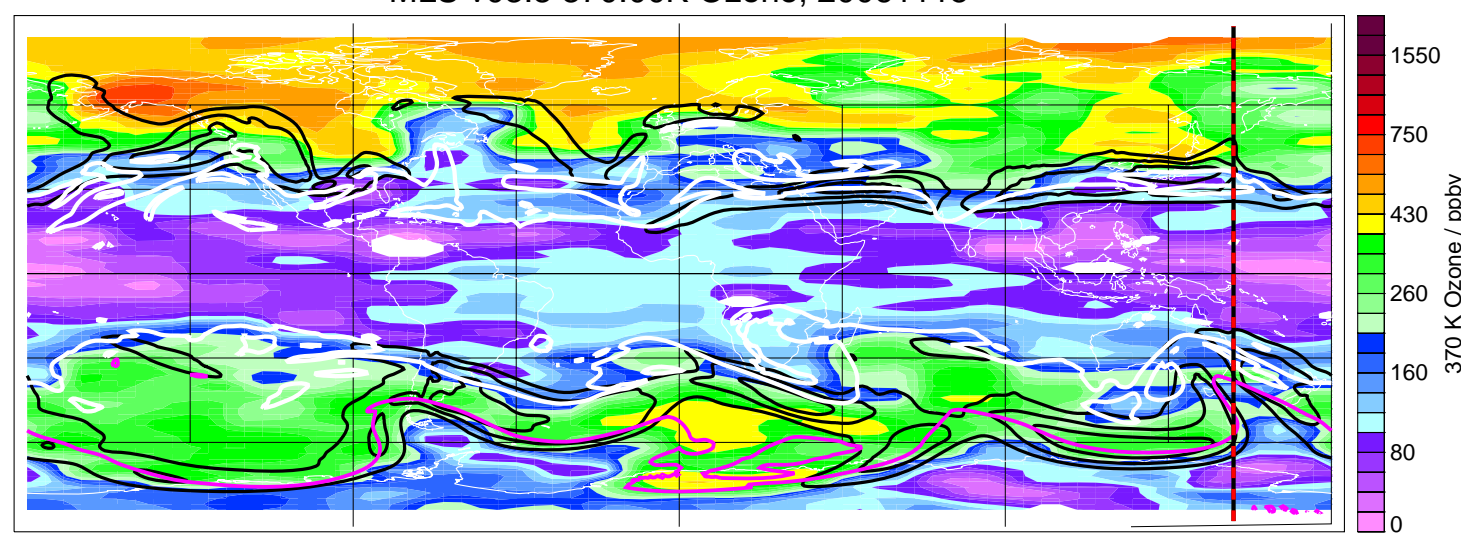

MLS v03.3 350.00K Ozone, 20090114

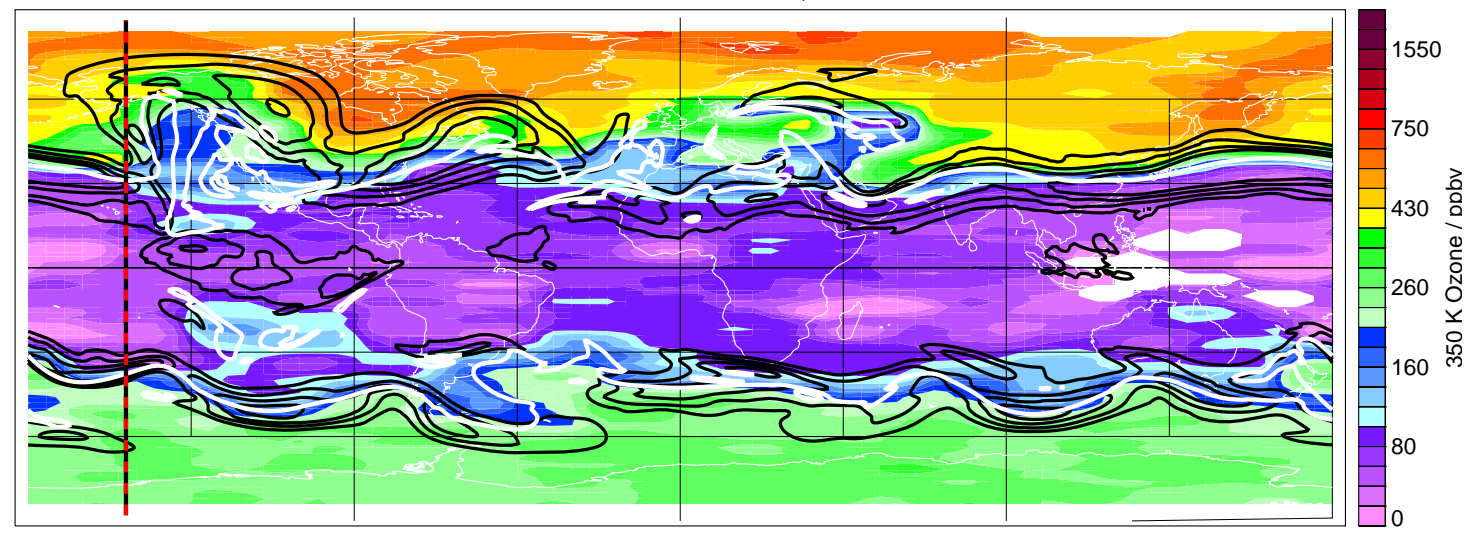

Fig. 1. Maps of MLS v3.3 $\mathrm{O}_{3}$ (colors; purples show low values, reds/browns high values) on isentropic surfaces in the UTLS. Thick white line shows the 4.5 PVU dynamical tropopause. Black contours show windspeeds of 30, 40, 50 and $60 \mathrm{~ms}^{-1}$, demarking the UTLS jets. Magenta contours on top plot are scaled PV of $1.2 \times 10^{-4} \mathrm{~s}^{-1}$ (typically near the subvortex edge in polar winter and spring). Maps are for 15 November 2006 at $370 \mathrm{~K}$ (top) and 14 January 2009 at $350 \mathrm{~K}$ (bottom). Dashed black/red lines show the longitudes of jet cross-sections shown in Fig. 2.

multiple cores at some longitudes, with corresponding complexity in the PV contours; its strength also varies greatly with longitude. Equivalent latitude (EqL) calculated from $\mathrm{PV}$ is a very useful coordinate in the polar winter stratosphere where, since the circulation is organized by a single, simplyconnected jet of relatively uniform strength around each EqL contour, it not only accurately segregates different air masses but also provides a complete description of the relationships of those air masses to the jet structure. In addition, as a dynamical coordinate, EqL indicates where PV conservation does and does not hold; non-conservation of PV is associated with irreversible transport. While an EqL coordinate still shows the boundary between different air masses in an average sense (around an EqL contour) in the UTLS, it can obscure the details of the relationships of those air masses to the complex, discontinuous system of jets, and associated variations in trace gas distributions and gradients around $\mathrm{EqL}$ contours.
Other methods, based on, e.g., gradients in total ozone (e.g., Hudson et al., 2003; Follette-Cook et al., 2009) or changes in mean tropopause altitude (e.g., Tilmes et al., 2010) that have been used to separate air masses utilize the observation that large changes in trace gas concentrations and tropopause altitude take place across the upper tropospheric jets. They thus indirectly use the subtropical jet location to separate air masses, as noted by Tilmes et al. (2010). Kunz et al. (2011) used PV gradients as a function of EqL to determine the tropopause location on isentropic surfaces, and noted that the PV contour corresponding to the average maximum PV gradient closely follows the strongest upper tropospheric jets. Brioude et al. (2008) used a coordinate system based on PV in the vertical and the angle between the local PV surface and the horizontal (thus a measure of the $\mathrm{PV}$ gradient) to segregate $\mathrm{O}_{3}$ and $\mathrm{CO}$ measurements taken east or west of upper-level troughs, again using information that indirectly views the measurements in relation to upper 
tropospheric jets. Ray et al. (2004) examined aircraft $\mathrm{O}_{3}$ measurements with respect to the upper tropospheric jets by organizing them as a function of potential temperature $(\theta)$ and the difference in windspeed at the measurement location from the maximum windspeed.

In this paper, we describe a method of characterizing the upper tropospheric and subvortex jets that provides information on horizontal and vertical structure, location and extent. Our method is applied to daily synoptic fields, thus retaining information useful for case studies of particular events while building up a database of jet characteristics for use in climatological studies. The jet characteristics are also cataloged with respect to satellite and aircraft measurement locations to facilitate viewing 3-D trace gas data in relation to the UTLS jets. In Sect. 2 we describe the meteorological and trace gas datasets used. Section 3 describes the details of our jet characterization method and use of it to characterize conditions at satellite and aircraft measurement locations with respect to the jets; because the primary purpose of this paper is to describe our methods, this section comprises a large fraction of the essential content. Section 4 provides examples of studies using our jet characterization. These include examining some climatological characteristics of the jets and dynamical fields associated with them, and examples demonstrating how using the jet framework to view trace gas data from satellite and aircraft measurements can help improve our understanding of transport in the ExTL. Section 5 provides discussion and conclusions.

\section{Data}

\subsection{Meteorological data}

The primary meteorological data used here are from the NASA Global Modeling and Assimilation Office (GMAO) Goddard Earth Observing System Version 5.1.0 and Version 5.2.0 data assimilation system analyses (collectively referred to herinafter as GEOS-5). These comprise the operational products, and the MERRA (Modern Era Retrospective-analysis for Research and Applications) reanalysis; the latter extends back to 1979. The GEOS-5.2.0 system is described by Reinecker et al. (2008, 2011). GEOS5 uses the Gridpoint Statistical Analysis method of Wu et al. (2002), a 3-D-Variational system, and a six-hour analysis window. The interface between the observations and the general circulation model (GCM) is performed using the incremental analysis update (IAU) approach (Bloom et al., 1996), which avoids shocking the model, thus producing smoother analyses. GEOS-5 analyses are provided on 72 model levels from the surface to $0.01 \mathrm{hPa}(\sim 75 \mathrm{~km})$, on a $0.5^{\circ}$ latitude by $0.6667^{\circ}$ longitude grid. The vertical resolution in the UTLS is near $1 \mathrm{~km}$. Comparisons of UTLS jets in GEOS-5 with those in other meteorological analyses show overall good agreement; a detailed assessment of differences between sev- eral meteorological analyses in this region, and the potential impact of such differences on future work, will be described in a follow-on paper as part of our climatological studies.

\subsection{Satellite datasets: Aura MLS and ACE-FTS}

Jet and tropopause characterization is currently being done for the measurement locations of instruments on NASA's Earth Observing System (EOS) Aura satellite, and from the Canadian Space Agency's Atmospheric Chemistry Experiment (ACE, also known as SCISAT-1) satellite.

Aura is in a $98^{\circ}$ inclination orbit. Jet and tropopause information has been cataloged for all measurements from the Microwave Limb Sounder (MLS) and some test cases for the High Resolution Dynamics Limb Sounder (HIRDLS); work is in progress to produce this information for the Tropospheric Emission Spectrometer (TES) data. The Aura examples shown here are from MLS data.

The Aura MLS fields-of-view point in the direction of orbital motion and vertically scan the limb in the orbit plane, leading to data coverage from $82^{\circ} \mathrm{S}$ to $82^{\circ} \mathrm{N}$ latitude on every orbit. MLS measures millimeter- and submillimeterwavelength thermal emission from the limb of Earth's atmosphere. Detailed information on the measurement technique and the MLS instrument on the EOS Aura satellite is given by Waters et al. (2006). Vertical profiles are measured every $165 \mathrm{~km}$ along the suborbital track and have a horizontal resolution of $\sim 200-300 \mathrm{~km}$ along-track and a footprint of $\sim 3-9 \mathrm{~km}$ across-track. Data processed with the recentlyreleased version 3.3 (v3.3) MLS data processing algorithms are shown here; the quality of these data and improvements over v2.2 are described by Livesey et al. (2011). Notable changes in the UTLS for the species shown here include retrieval of $\mathrm{O}_{3}$ on twice as many pressure levels, resulting in slightly better vertical resolution (now nominally $\sim 2.5$ to $3 \mathrm{~km}$ in the UTLS), and elimination of a low bias in $\mathrm{HNO}_{3}$ at all levels up to the middle stratosphere and of a large high bias in $\mathrm{CO}$ at the lowest retrieval levels. However, $\mathrm{O}_{3}, \mathrm{HNO}_{3}$ and $\mathrm{CO}$ retrievals at the lowest levels are all more adversely affected by the presence of thick clouds than in v2.2, leading to unphysical spikes, especially in the tropics; procedures for screening such outliers in these products are given by Livesey et al. (2011). The vertical resolution of $\mathrm{HNO}_{3}$ and $\mathrm{CO}$ is nominally $\sim 3-4 \mathrm{~km}$ in the UTLS. Quality screening of the v3.3 MLS is done according to the recommendations of Livesey et al. (2011).

ACE (Bernath et al., 2005) was launched in August 2003. The primary instrument is the ACE-FTS, a Fourier transform spectrometer featuring high resolution $\left(0.02 \mathrm{~cm}^{-1}\right.$, corresponding to a $\pm 25 \mathrm{~cm}$ maximum optical path difference) and broad spectral coverage in the infrared $\left(750-4400 \mathrm{~cm}^{-1}\right)$. ACE-FTS works primarily in the solar occultation mode, collecting atmospheric limb measurements using the sun as a radiation source. V2.2 ACE-FTS $\mathrm{CO}, \mathrm{O}_{3}$ and $\mathrm{H}_{2} \mathrm{O}$ have been shown to be of high quality in the UTLS (Hegglin et al., 
2008). Version 3.0 ACE-FTS retrievals are used here; the retrieval method is similar to that for v2.2 (Boone et al., 2005), with improvements to the physical model and improved microwindow sets for the molecules. V3.0 ACE-FTS reprocessing is nearing completion. Initial quality checks on v3.0 data indicate improved behavior over v2.2 in the UTLS, though extensive validation has not yet been done.

\subsection{Winter storms aircraft data}

The Winter Storms aircraft measurement program (e.g., Szunyogh et al., 2002) was designed to assess the effects of ingesting targeted observations into numerical weather forecast models. To this end, numerous aircraft flights were conducted in 2000 through 2008, mainly in winter (January and February) and early spring (March), sampling storm systems in the Pacific Ocean between Hawaii and Alaska. An instrument on the flights in 2001 through 2007 measured $\mathrm{O}_{3}$ in the vicinity of jets associated with the storm systems. The fastresponse dual-beam UV absorption ozone photometer is described by Proffitt and McLaughlin (1983), and has a precision of 1 ppbv (parts per billion by volume); data were taken at $1 \mathrm{~Hz}$, resulting in a horizontal resolution of $200 \mathrm{~m}$. Ray et al. (2004) give further details on the Winter Storms flights through 2003, and use these and other aircraft data to develop climatologies of $\mathrm{O}_{3}$ near the subtropical jets.

\section{Jet identification and characterization methods}

\subsection{Upper tropospheric jet characterization}

Figure 2 shows two cross-sections of windspeed (taken at the longitudes marked in Fig. 1), one in Northern Hemisphere (NH) winter and the other in SH spring, with annotations pertaining to our method of characterizing the UTLS jets and their environment.

For a given "slice" (i.e., a 2-D section in some horizontal and some vertical coordinate; for present applications we use latitude and the vertical coordinate of the meteorological dataset), all maxima in windspeed that occur at pressure levels between 400 and $100 \mathrm{hPa}$ are identified in 2-D. An upper tropospheric jet is defined to exist wherever there is a windspeed maximum greater than $40 \mathrm{~m} \mathrm{~s}^{-1}$; the boundaries of the jet region are the points surrounding that (in both horizontal and vertical directions) where the windspeed drops below $30 \mathrm{~m} \mathrm{~s}^{-1}$. These values were selected using the criteria of Koch et al. (2006) as a guideline, and confirmed as realistic for a wide range of atmospheric conditions through examination of many cases in different seasons, years (spanning the 32-year record of the MERRA reanalysis), and dynamical conditions. When more than one maximum above $40 \mathrm{~m} \mathrm{~s}^{-1}$ appears within a given $30 \mathrm{~m} \mathrm{~s}^{-1}$ contour (as seen in both panels of Fig. 2), additional tests are applied to determine whether each is identified as a separate jet core: if the distance between two maxima is greater than $15^{\circ}$, or the decrease in windspeed along the line between them is greater than $25 \mathrm{~m} \mathrm{~s}^{-1}$, then they are cataloged as two separate jet cores. Figure 2 shows an example in the NH winter of two such maxima that are identified as separate jet cores, and two in the SH spring that are not. A large number of windspeed cross-sections were examined to verify that the criteria chosen resulted in an identification of the same jet cores that would be selected "by eye". The human eye and visual processing circuitry being a highly sophisticated system for this type of decision-making (e.g., von Ahn et al., 2008; Sajda et al., 2010), no single set of simple criteria automatically applied will always produce a result that agrees with visual inspection, but we have tuned the parameters to try to maximize agreement. The code is formulated so that all parameters can easily be adjusted, facilitating evaluation of special cases or possible trends that may warrant re-evaluation of these choices.

This procedure for characterization of the jet is currently being done at each longitude of interest, with latitude as the horizontal coordinate. However, there is nothing inherent in the procedure that ties it to latitude as a horizontal coordinate. We have, for example, looked at cases where we applied it along satellite orbit tracks; also, as noted below, a useful application for case studies may be to use the jet characterization procedure along a line from a measurement location perpendicular to the wind direction. Likewise, though the procedure does not require a particular vertical coordinate, the meteorological datasets (initially GEOS-5, including MERRA reanalysis) are, when possible, used on their native model grid so as to minimize interpolations and hence preserve, as much as possible, the full information content of the data.

The jets are identified separately in the $\mathrm{NH}$ and $\mathrm{SH}$, with up to five jets in a hemisphere in a given slice cataloged, ordered from strongest to weakest in that hemisphere ("N" and "S" numbered marks in Fig. 2). Along with the position (given in horizontal and vertical gridpoints and in latitude/longitude and altitude/pressure/ $\theta$ ) of the jet core and edges of the jet region (edges shown as yellow dots in Fig. 2), a number of other fields are cataloged at the jet locations, including horizontal wind components, temperature, vertical temperature gradient $(d T / d z)$, PV, and relative vorticity. $d T / d z$ is calculated from the GEOS-5 temperature and geopotential height (GPH), the latter being used to obtain the altitudes. PV is provided in the GEOS- 5 dataset, and relative vorticity is derived using that and $\theta$ calculated from the temperature to get the static stability term.

Since both the upper tropospheric jets and trace gas distributions are closely associated with characteristics of the tropopause, we have also compiled a detailed catalog of tropopause characteristics, and include in the jet catalog the vertical distance of the jet core from the primary tropopauses (see definitions in Sect. 3.3). 

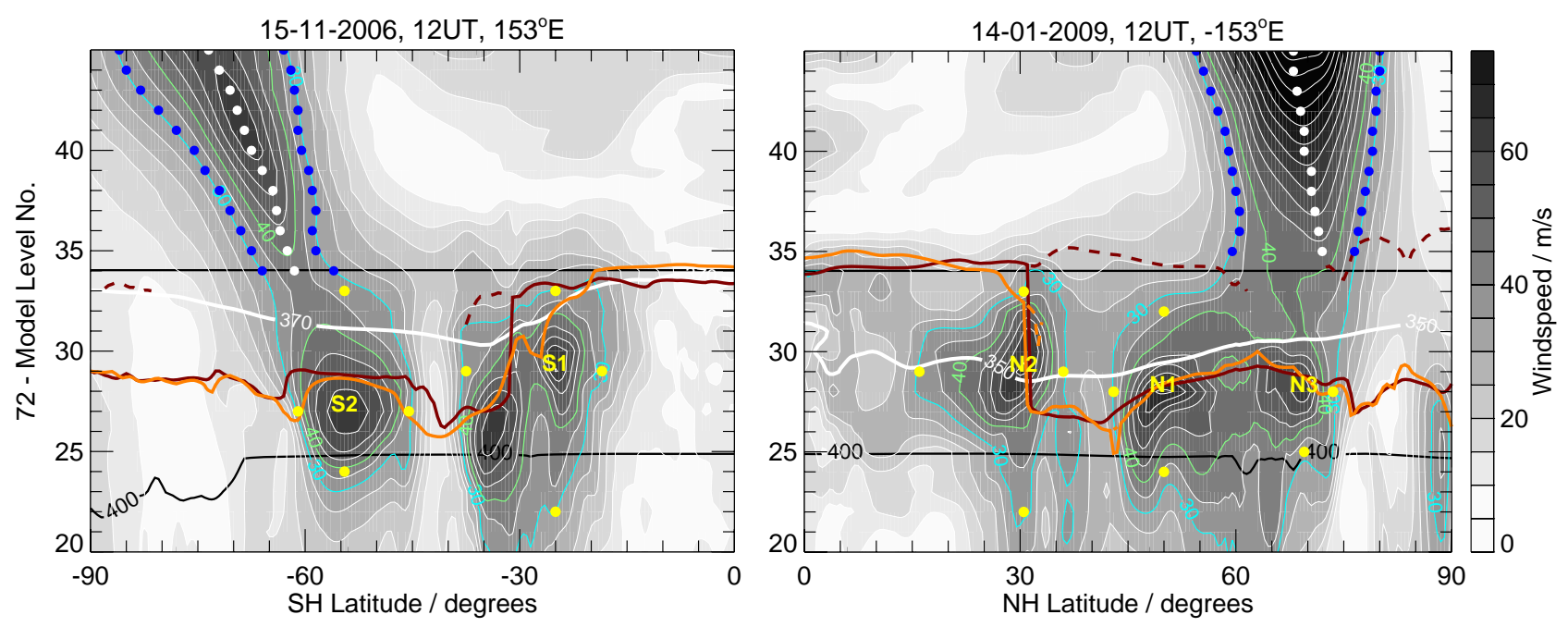

Fig. 2. Cross-sections of windspeed (grey shading; green contour is $40 \mathrm{~ms}^{-1}$, cyan contour $30 \mathrm{~ms}^{-1}$ ) at the locations shown in Fig. 1, with jet and tropopause classification information overlaid; fields are displayed on the GEOS-5 model levels in the vertical. Yellow letter/number combinations indicate the locations of jet cores according to the classification scheme described in the text, lowest numbers are for strongest jets in each hemisphere; yellow dots indicate the identified locations of the edges of the jet region (at gridpoints, thus not exactly matching contours). Orange lines show the 4.5 PVU dynamical tropopause and dark red lines the WMO (thermal) tropopause; dashed lines show the secondary tropopause, if present. White dots show the subvortex jet maximum and blue dots the edges of the subvortex jet. Thin black nearly-horizontal lines show 400 and $100 \mathrm{hPa}$ pressure levels (the $400 \mathrm{hPa}$ contour is not horizontal because the model levels are terrainfollowing at that pressure). Thick white line shows the $370 \mathrm{~K}(350 \mathrm{~K})$ potential temperature level on the left (right) plot, the levels of the ozone plots in Fig. 1.

For use in developing jet climatologies, the upper tropospheric jet cores have been identified and cataloged for every longitude in the GEOS-5 analyses' 12-UT data fields, thus providing daily jet characterization from 1979 through the present. In the future, we will add jet/tropopause information for the 0-, 6- and 18-UT fields to the catalog to facilitate study of individual transient events.

A separate catalog is compiled for use with satellite datasets, wherein the identification and characterization is carried out at the time and longitude of every datapoint (meteorological analysis slices are interpolated linearly in longitude and time). The differences between each characteristic (horizontal and vertical position, and dynamical fields) at the jet core and edge locations and that at the measurement location are cataloged. In addition, the vertical distance of the measurement locations from the tropopause (defined in several ways, see Sect. 3.3 below) is recorded.

\subsection{Subvortex jet characterization}

The subvortex jet (the lowest part of the stratospheric polar night jet) can extend into the lowermost stratosphere, and thus may influence transport (including extratropical STE) in that region; there is also evidence that it may play a role in determining variability of the upper tropospheric jets (e.g., Bordi et al., 2007). To examine the subvortex jet in the region of influence of the upper tropospheric jets, we character- ize the stratospheric jet where it extends into the lowermost stratosphere as a function of altitude rather than (as for the upper tropospheric jets) identifying a single jet core. To that end, we use the slices of windspeed and of the zonal wind component in each hemisphere to identify the most poleward westerly windspeed maximum at each level (on whatever vertical grid is being used) that exceeds $30 \mathrm{~m} \mathrm{~s}^{-1}$, and record the location and characteristics at that maximum and at the $30 \mathrm{~m} \mathrm{~s}^{-1}$ contour crossings on either side of it as the jet maximum and edges (white and blue dots, respectively, on Fig. 2). Occasionally several local maxima will be identified in a single region with windspeeds over $30 \mathrm{~m} \mathrm{~s}^{-1}$, and small undulations in the windspeed can lead to ambiguity in determining the appropriate maximum location (e.g., a case where the windspeed drops slightly, then increases to a higher value, where the eye would identify the higher value as the appropriate jet maximum); to deal with this, we do not count two maxima as separate unless the windspeed in between them drops by at least $5 \mathrm{~m} \mathrm{~s}^{-1}$.

Often, the bottom of the subvortex jet will extend down to the level of the upper tropospheric jets, and, if no further criteria were applied, might be confused in the automated identification with the top of an upper tropospheric jet (e.g., with N3 or S2 in Fig. 2). To alleviate this, we first identify the subvortex jet at levels down to a pressure near $300 \mathrm{hPa}$. We then start working down from the level nearest $80 \mathrm{hPa}$, and test whether the windspeed of the jet maximum is higher 
at higher altitude. The lowest altitude level where this is the case is defined as the bottom of the subvortex jet, and any jet below that is assumed to be part of an upper tropospheric jet.

As for the upper tropospheric jets, the choice of vertical coordinate is immaterial to the identification of the subvortex jets. However, the use of latitude as a horizontal coordinate is prescribed, since the definition is relative to the pole. In situations where the polar vortex/subvortex is shifted completely off the pole, the polar vortex boundary crosses the same longitude twice (on either side of the vortex), resulting in an easterly jet poleward of the westerly one that is initially identified as the subvortex jet. In such cases, the core and edge characteristics of that easterly jet are also cataloged, since it is simply the portion of the same jet as the westerly one on the opposite side of the subvortex. This also ensures accurate characterization of the subvortex jets if the stratospheric polar vortex splits down to the levels we are considering here; this may occur during particularly strong stratospheric sudden warmings (e.g., Manney et al., 2009a).

For climatological studies (i.e., when defining jets directly on the meteorological analyses' grids), and for datasets (such as those from aircraft) that do not provide profile information, the subvortex jet is identified in each hemisphere on the meteorological datasets' native levels (or the levels on which the dataset is provided to the user). For catalogs of subvortex jet information for use with datasets that provide profile information (e.g., the satellite datasets considered here), the levels used are the ones at which the profile data are provided, and the differences between characteristics at the jet location and the measurement location on each such level are cataloged.

\subsection{Tropopause identification}

Along with the jet characterization, we compile comprehensive tropopause information, identifying the dynamical tropopause using four PV values (2.0, 3.5, 4.5 and 6.0 potential vorticity units, PVU) and the thermal tropopause using the WMO definition. The PV values for the dynamical definitions span the range of those that have been widely used, and values of 3.5-4.5 PVU have been shown to match well with the WMO tropopause at high latitudes (e.g., Highwood et al., 2000; Schoeberl, 2004); Pan et al. (2004) and Krebsbach et al. (2006), among others, found that 4.5 PVU closely matched the sharp vertical gradients in ozone across the tropopause. Kunz et al. (2011) showed that maximum PV gradients on isentropic surfaces occurred in a broad range of $\mathrm{PV}$ values between 1.5 and 5.0 PVU, increasing with increasing potential temperature. Following Manney et al. (2007), and references therein, the dynamical tropopause in the tropics is defined as the $380 \mathrm{~K}$ isentropic surface, and joined with the PV-defined one where the PV contour used for the definition rises above $380 \mathrm{~K}$. Comparison of the solid orange (primary 4.5 PVU dynamical tropopause) and dark red (primary thermal tropopause) lines in Fig. 2 shows a typical level of agreement between dynamical and thermal tropopauses, with closer agreement away from strong upper tropospheric jets, consistent with previous studies (Pan et al., 2004; Homeyer et al., 2010, and references therein). The dashed dark red and orange lines are secondary tropopauses, and show typical examples of extensive regions with double thermal tropopauses, and limited regions at tropopause folds of double dynamical tropopauses.

Multiple thermal tropopauses at a given latitude, longitude and time are identified if $d T / d z$ drops below $-2 \mathrm{~K} \mathrm{~km}^{-1}$ after (that is, at a higher altitude) remaining below it for at least $2 \mathrm{~km}$ (to fulfill the WMO definition), and then rises above $-2 \mathrm{~K} \mathrm{~km}^{-1}$ again; a larger drop has been required in some studies using high resolution temperature profiles, but Randel et al. (2007b) showed that the criteria used here result in a better match of multiple tropopauses identified in (relatively coarse-resolution) meteorological analyses with those seen in high-resolution measurements. Up to four tropopauses may be defined on a profile, if there are that many locations that fulfill the definition at altitudes below $\sim 15 \mathrm{hPa}$ pressure; in practice, double thermal tropopauses are common, triple ones rare, and we have not seen cases with more than three. Multiple dynamical tropopauses can also occur in the extratropics (e.g., on either side of a deep tropopause fold), but they are not as common or extensive as the thermal ones, and tend to be more closely spaced and confined to locations nearer the upper tropospheric jets where tropopause folds are common. These are also cataloged when present.

Tropopause locations (altitude, pressure, and $\theta$ ) and temperatures are cataloged at each gridpoint for the meteorological analyses with which we are working. For use with satellite measurements, the meteorological analyses' temperatures are interpolated in latitude, longitude and time to the measurement coordinates, and the tropopauses identified and cataloged for those positions.

\section{Applications}

Examples of several initial applications of our jet characterization methods are given below. In these studies, we focus primarily on the upper tropospheric jets and analyses pertinent to studying their relationships to trace gas distributions.

\subsection{Jet variability and climatology}

Figures 3 and 4 show examples of the monthly distributions of upper tropospheric jets for January and November, illustrating characteristic patterns of the jets in $\mathrm{NH}$ winter/SH summer and $\mathrm{NH}$ fall/SH spring. The maps in Figs. 3 show the frequency and average windspeed of all upper tropospheric jets during January 2009 and November 2006. Several general features can be noted that are consistent with previous studies of jet climatology. In the $\mathrm{NH}$, a strong, persistent (that is, high windspeeds/high frequencies) subtropical jet 

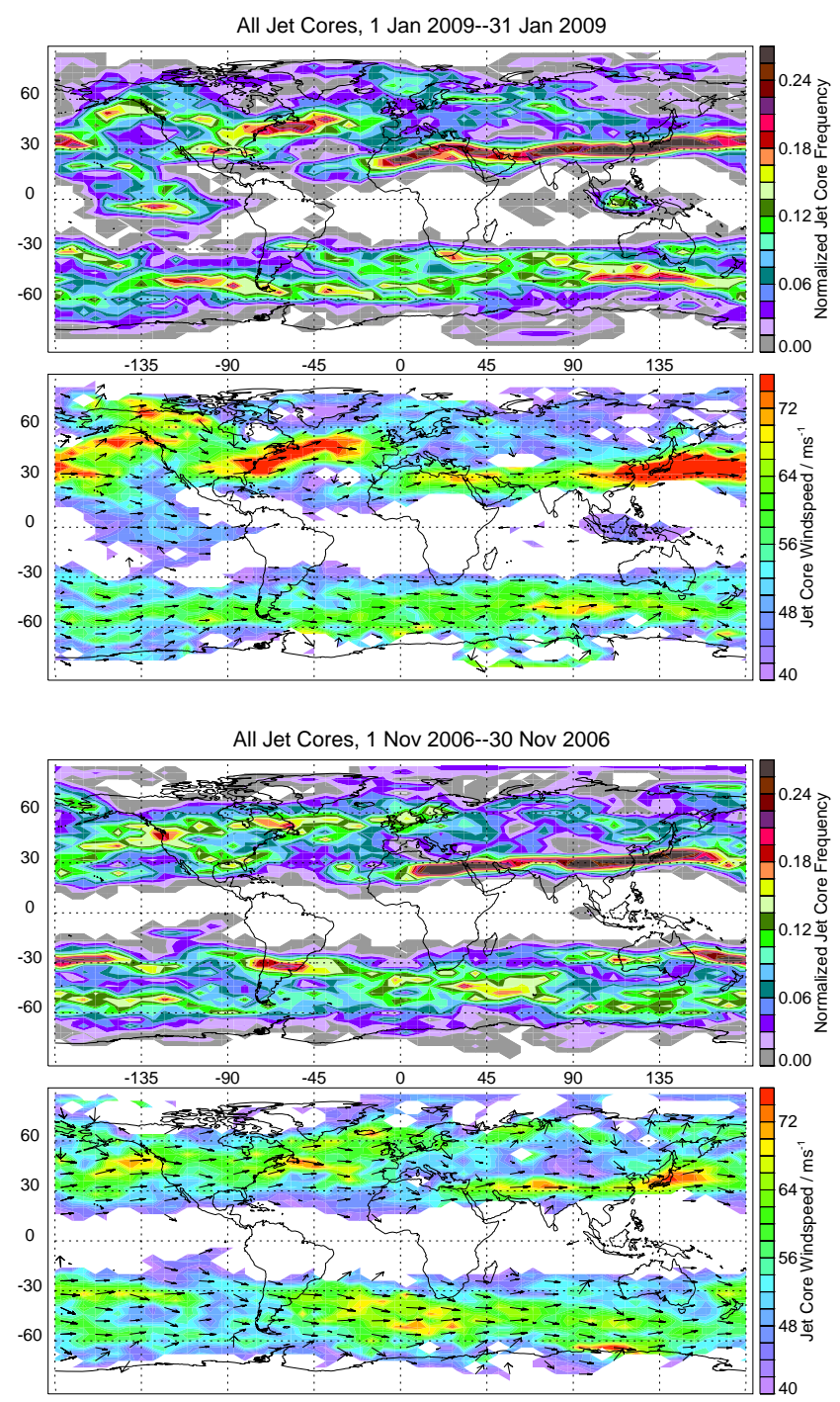

Fig. 3. Maps of jet frequency (top panels of pairs), normalized by number of days and number of bins (and multiplied by 100), and average windspeed (bottom panels of pairs) at the jet cores for January 2009 (top pair) and November 2006 (bottom pair). Wind vectors are overlaid as black arrows on the windspeed panels. Purples/blues show low values, reds high values.

spans the Eastern Hemisphere in both seasons shown, with a more complex and variable pattern of jets over North America and the Atlantic Ocean. The pattern with a high frequency of both subtropical and polar jets merging into a region where a single strong high latitude jet is most common seen in January 2009 between $\sim-160$ and $-20^{\circ} \mathrm{E}$ is typical of NH winter and is consistent with the results of Strong and Davis (2008a). The longitudes of this pattern show strong interannual variability, and such a feature is stronger in the recent winters that had strong and prolonged stratospheric sudden warmings. This pattern of jet frequency is associated with upper tropospheric ridges and blocking events, which tend to be stronger in winters with strong stratospheric sudden warmings (e.g., Martius et al., 2009) and are implicated in forcing those events (e.g., Manney et al., 2009b,a; Coy et al., 2009; Martius et al., 2009). An interesting feature in the $\mathrm{NH}$ winter is a persistent equatorial westerly jet over $\sim-160$ to $-120^{\circ} \mathrm{E}$; in this longitude region there are thus frequently three jets. Similar equatorial jets are apparent in other $\mathrm{NH}$ winter months, and in individual cases examined appeared to be associated with tongues of $\mathrm{NH}$ mid-latitude PV drawn out into the tropics. This is the representation in the jet climatology of the well-known "westerly duct" in the tropical Pacific that is one of two regions of persistent mean westerlies in the tropics where cross-equatorial propagation of Rossby waves is favored (e.g., see discussion in Homeyer et al., 2011). The westerly ducts are associated with both equatorward and poleward Rossby-wave breaking (e.g., Waugh and Polvani, 2000); tongues of PV drawn out from midlatitudes into, and into midlatitudes from, the tropics are signatures of that wave breaking. In the Southern Hemisphere, a concentric pattern of persistent subtropical and polar jets is apparent at most longitudes in both seasons shown, consistent with the results of, e.g., Koch et al. (2006) and Bordi et al. (2007, 2008); also consistent with those results is the finding that the polar jet is more persistent (higher frequencies) than the subtropical jet in SH summer. In general, higher jet frequencies are associated with stronger jets, implying a physical relationship between jet frequency and windspeed, as discussed by Strong and Davis (2008a).

Figure 4 shows the jet frequency as a function of altitude and latitude in two Januaries and two Novembers, along with the frequency of the subvortex jet. January 2005 was in the midst of a very cold, quiet stratospheric winter (e.g., Manney et al., 2006), while the strongest, most-prolonged stratospheric sudden warming on record occurred in January 2009. In November 2006, a strong stratospheric polar vortex extended unusually far down into the lowermost stratosphere, in contrast to a more typical lower extent in November 2005 (Santee et al., 2011). The characteristic well-known pattern of a high-altitude (most frequently near 11-12 km) subtropical jet and a lower altitude (typically near $9-10 \mathrm{~km}$ ) polar jet is seen in these figures. As was also evident in the maps in Fig. 3, the polar jet is usually stronger and more persistent than the subtropical jet in the $\mathrm{SH}$, especially in summer, but also sometimes in spring (e.g., November 2005); this is in contrast to the $\mathrm{NH}$, where the subtropical jet is nearly always most persistent. In the SH (more prominent in spring) the subtropical jet shows a double-peaked frequency pattern, with a higher altitude, lower latitude peak near $13 \mathrm{~km}$ and the second (usually stronger) peak slightly poleward of it near $11 \mathrm{~km}$. Significant subvortex jet frequencies extend much further down in the SH (to $\sim 11-13 \mathrm{~km}$, depending on the year) than in the $\mathrm{NH}$ (typically $\sim 14 \mathrm{~km}$ ), reflecting the stronger, deeper, more persistent SH polar vortex. This is significant to the transport and exchange of trace gases since 

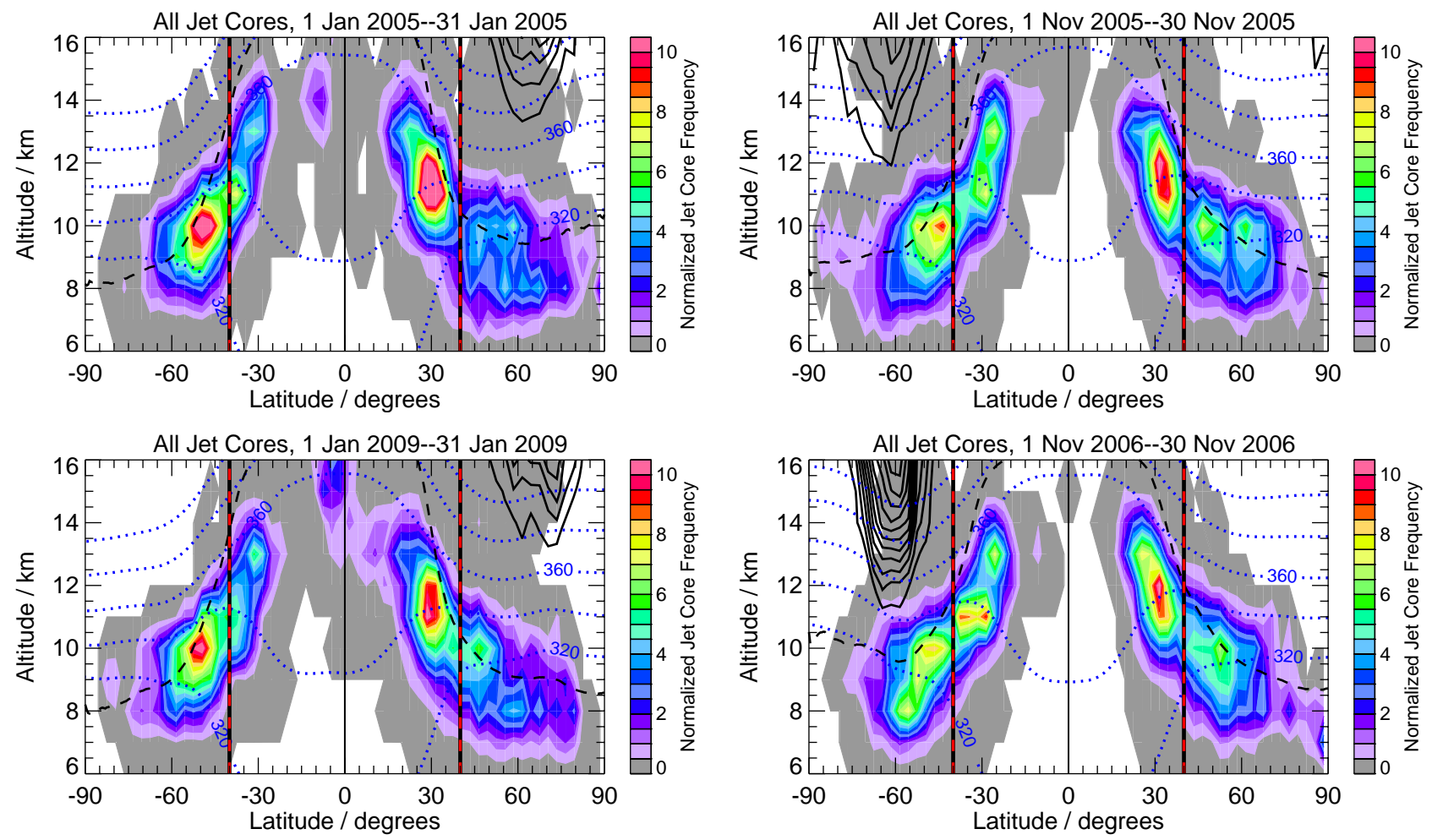

Fig. 4. Cross-sections as a function of altitude and latitude of upper tropospheric (colors) and subvortex (black contours) jet frequency (normalized by number of days and number of bins, and multiplied by 100) during January 2005 and 2009 (top and bottom left, respectively) and November 2005 and 2006 (top and bottom right, respectively). Vertical dashed black/red lines are at $\pm 40^{\circ}$ latitude. Dashed black line shows the mean (over longitudes where a jet core exists) 4.5 PVU tropopause altitude. Dotted blue lines are zonal mean potential temperature contours, from 320 to $400 \mathrm{~K}$ by $20 \mathrm{~K}$. Greys/purples show low values, oranges/reds high values.

the SH subvortex typically extends well into the altitude region influenced by the subtropical upper tropospheric jet, resulting in a very different pattern of transport barriers in the $\mathrm{SH}$ lowermost stratosphere than that in the NH (Santee et al., 2011). Also as a consequence of the depth of the SH subvortex jet, as seen in Fig. 2 (left panel), the subvortex jet often merges smoothly with the top of an upper tropospheric jet.

The jet distributions shown here indicate strong interannual variability in both the upper tropospheric and subvortex jets. For example, compared to that in 2009 , the NH subtropical jet in January 2005 is more persistent than in January 2009 and more often extends to higher altitudes; the NH 2005 polar jet has a broader distribution than that in 2009, with several separate peaks indicating more variability in the polar jet. The polar and subtropical jets are also more separated in January 2005 than in January 2009. These patterns arise from the persistent strong ridges (implicated in forcing the strong stratospheric sudden warming) in January 2009, which are associated with the excursion of a sector (or sectors) of the subtropical jet to high latitudes, thus decreasing the frequency of a subtropical jet and increasing the frequency of a polar jet; the separation is less in 2009 because the patterns reflect the evolution of a single jet shifting smoothly to different latitudes, whereas in 2005 the patterns more often reflect the concurrent existence of two separate jets. In the SH, significant interannual differences are also seen in the upper tropospheric jets, but the most striking difference is the contrast between the lower extent and strength of the subvortex jet in November 2005 and 2006. As noted by Santee et al. (2011), the depth and strength of the SH subvortex in 2006 were instrumental in the development of an unusually large Antarctic ozone hole that year.

The consistency of the patterns and seasonal variations seen in these upper tropospheric jet distributions with previous results provides confidence that our characterization of the jets is reliably capturing their climatological distributions and seasonal variability. A detailed climatology of the UTLS jets in the MERRA reanalyses is being completed (Manney et al., 2011).

In cases where there are high jet frequencies in both the subtropical and the polar upper troposphere, there is usually a distinct minimum in frequency located near $40^{\circ}$ latitude. This observation is used below to provide a very simple method for distinguishing the subtropical and polar jets for use as coordinates: the subtropical jet is defined to be the strongest westerly jet equatorward of $40^{\circ}$, and the polar jet 
the strongest jet poleward of $40^{\circ}$. In the following section, we illustrate some of the dynamical characteristics of the upper tropospheric jet regions that are expected to be relevant to transport processes determining trace gas distributions in the UTLS and to the use of jet-relative coordinates.

\subsection{Characterization of dynamical fields with respect to the jets}

EqL and $\theta$ are commonly used as coordinates in the stratosphere to separate distinct air masses and to highlight condition-space coverage of sparse datasets (Manney et al., 2007 , and references therein). An EqL/ $\theta$ coordinate is very effective in this context because the stratospheric circulation is usually characterized by a single, simply-connected (most often, in fact, circumpolar) jet that represents a continuous relatively uniform transport barrier around the globe. While EqL/ $\theta$ coordinates have also been used for a number of studies focusing on the UTLS (e.g., Hoor et al., 2004; Hegglin et al., 2006), it is unclear how completely they represent the strongly varying transport barriers in the undulating flow defined by the complex of upper tropospheric jets. In addition, because the upper tropospheric jets are typically discontinuous in longitude, the dynamical (and hence transport, Sect. 4.3) environment in regions with and without strong jets is expected to be very different, and combined analysis of such disparate regions gives a blurred view of the relationships of dynamical and transport features in the jet regions.

Figure 5 shows EqL and $\theta$ fields plotted with the distance from upper tropospheric jets as a coordinate system (latitude difference in the horizontal and altitude difference in the vertical) during August 2007; fields have been plotted separately using the subtropical and polar jets (as defined by the simple $40^{\circ}$ latitude division described above) as the origin of the coordinate system. For this period, the average altitudes and latitudes of the subtropical jet cores are $-31^{\circ}, 11 \mathrm{~km}$ in the $\mathrm{SH}$ and $32^{\circ}, 13 \mathrm{~km}$ in the $\mathrm{NH}$; average polar jet latitudes and altitudes are $-59^{\circ}, 9 \mathrm{~km}$ and $56^{\circ}, 11 \mathrm{~km}$, in the $\mathrm{SH}$ and $\mathrm{NH}$, respectively. If $\mathrm{EqL}$ and $\theta$ coordinates provided a similar composite of the air masses in the regions with well-defined upper tropospheric jets (regions without are not included in these plots), the EqL field would appear as nearly vertical contours and the $\theta$ field as nearly horizontal contours; to the degree that this is the case, similar information may be obtained from viewing fields in either coordinate system. In both summer and winter hemispheres, and in both the polar and subtropical jet cases, EqL and $\theta$ form an approximately vertical/horizontal grid above $\sim 6-8 \mathrm{~km}$ above the upper tropospheric jet core. In the SH, where it is winter, that "grid" is especially regular across the strong subvortex jet, illustrating the dynamical patterns that make EqL/ $\theta$ coordinates particularly useful in regions where the stratospheric polar night jet is the dominant feature of the circulation. Below about $6 \mathrm{~km}$ above the upper tropospheric jet core, the EqL contours depart strongly from the vertical and the $\theta$ contours

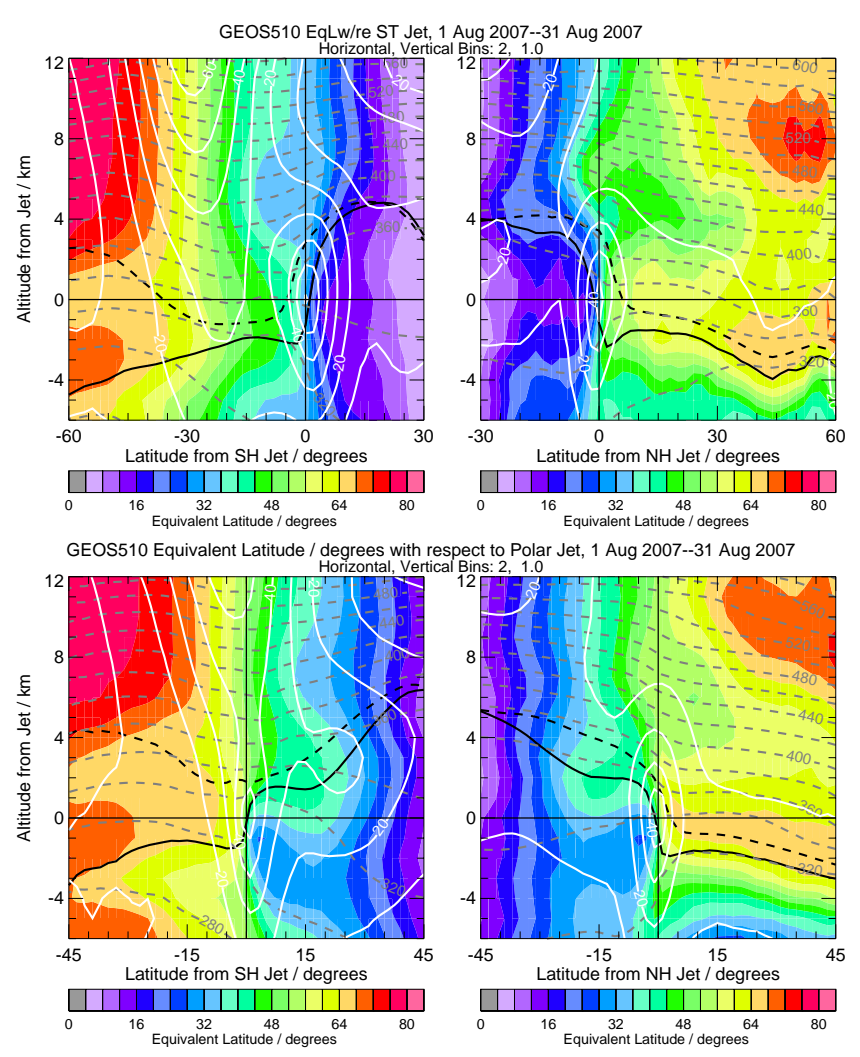

Fig. 5. Plot of GEOS-5 EqL (colors) and potential temperature $(\theta$, grey dashed contours) averaged for August 2007 with latitude and altitude from the upper tropospheric jets as horizontal and vertical coordinates. Northen and Southern Hemispheres are shown separately on *right* and *left*. Top panels show fields with respect to the subtropical jet (the strongest jet equatorward of $40^{\circ}$ latitude) and bottom panels with respect to the polar jet. White overlays are GEOS-5 windspeed, black overlays are 4.5 PVU (solid) and WMO (dashed) primary tropopauses. The data were binned and averaged on a $2^{\circ}$ latitude by $2 \mathrm{~km}$ altitude grid. Greys/purples show low values, oranges/reds high values.

from the horizontal. This altitude is near or above the tropical tropopause, so the entire lowermost stratosphere is a region where EqL/ $\theta$ coordinates do not organize the fields in a similar manner to upper tropospheric jet coordinates; the jetbased view may thus provide additional insights on the dynamics in the vicinity of the jets. The higher EqL values extending towards the jet from the poleward side just below the subtropical jet (top panels) and near or just above the polar jet (bottom panels) suggest preferred regions for advection and may thus associated with tropospheric or stratospheric intrusions (e.g., Pan et al., 2009). (Note that the regions where EqL does not increase monotonically poleward of the jet, for example in the upper right of the top NH panel of Fig. 5, are generally far from the jet influence, and thus the jets are not a strong influence on the circulation in those regions.) 
The information in this jet-coordinate framework is even more distinct from that in an EqL view (or any other coordinate that averages around the globe, e.g., a zonal mean view) in that it goes beyond a simple coordinate transformation by excluding regions without a strong jet. In some sense, this selects the geographic regions where $\mathrm{EqL}$ is most useful as a coordinate. This is evident in that the latitudinal EqL gradients across the jet core (from $\sim 4 \mathrm{~km}$ below to $4 \mathrm{~km}$ above for the subtropical jet, and over a more limited region for the polar jet) are quite strong, suggesting an effective transport barrier there, so that EqL would be effectively segregating different air masses; it is not clear that this would be the case in regions without a strong jet. The ability to not only compare the representation in the two coordinate systems, but also to use the jet information to assess the representation of strong versus weak jet regions in EqL coordinates may thus provide new insights on the dynamics both near and distant from strong jets. The details of the EqL/ $/$ /jet relationships vary with season and hemisphere; though the general features are usually similar to those shown here, in some seasons (e.g., $\mathrm{NH}$ spring/early summer, not shown) the EqL contours do not depart from verticality as strongly as in the case shown in Fig. 5. However, even in those cases, EqL would be expected to mingle the characteristics of strong and weak jet regions. As will be explored below (Sect. 4.3), we thus expect to get a substantially different picture of trace gas distributions when we view them with respect to the upper tropospheric jets.

Note that the polar jet is washed out in the plots with respect to the subtropical jet and vice versa, indicating that during this period the polar and subtropical jets are not typically strong at the same longitudes or times or both. Because the latitudinal distance between the two jets is typically $20-30^{\circ}$, the local circulation in the region is determined primarily by the characteristics of the closest jet (modulated by the jets' relative strength and width). The large drop in tropopause altitude (by $\sim 6-7 \mathrm{~km}$ ) across the subtropical jet, with the tropopause $4-5 \mathrm{~km}$ above the jet equatorward of it and 2$3 \mathrm{~km}$ below poleward of it, is consistent with the classical picture of the tropopause break; a similar but smaller $(\sim 3-$ $4 \mathrm{~km}$ ) drop seen across the polar jet in the plots with that jet as the origin is consistent with the supposition that the subtropical jet is often weaker or non-existent (with a correspondingly weaker change in tropopause height across it) when a strong polar jet is present. The ability to apply a variety of selection criteria to the jets used as coordinates will provide a valuable tool for examining dynamics and transport in relation to upper tropospheric jets with differing characteristics and origins (e.g., jets that are primarily radiatively versus eddy driven, a distinction often approximately accomplished by the classification of subtropical and polar jets; Bordi et al., 2007, and references therein).

Figure 6 shows examples of several dynamical fields in subtropical jet coordinates, for the same month shown in Fig. 5. As mentioned earlier, because the jet coordinate view excludes regions without a strong jet, it provides a focused
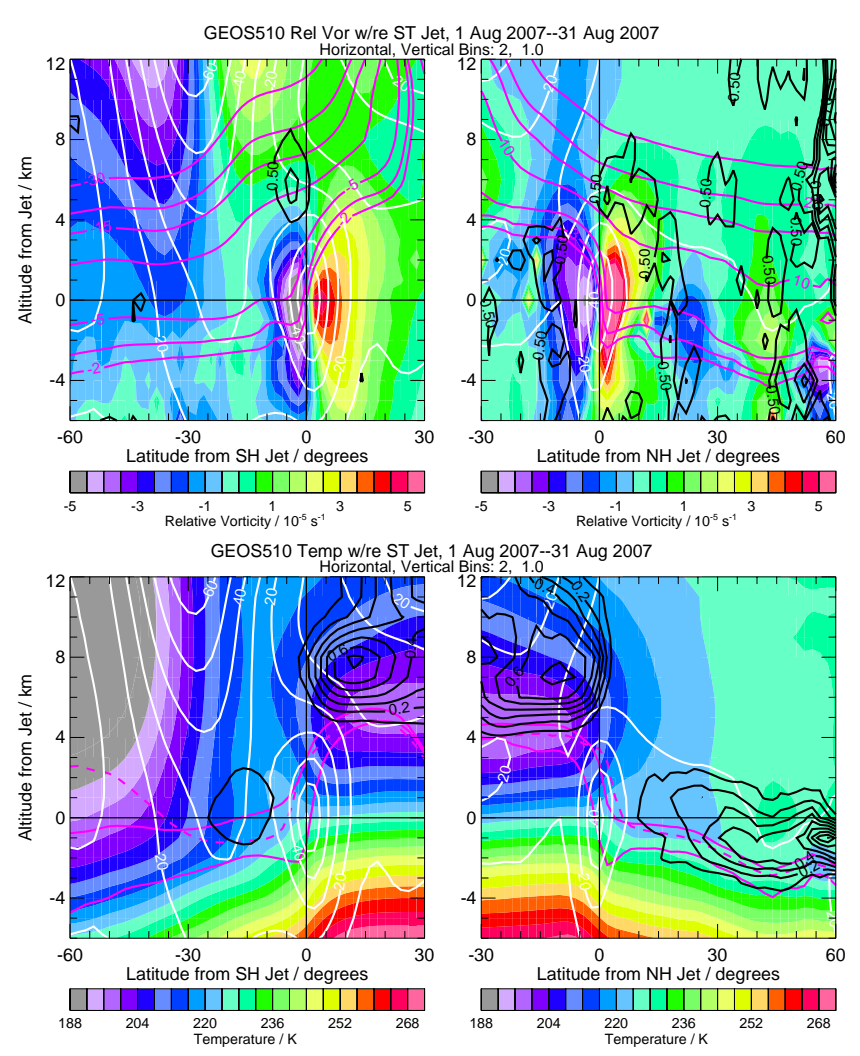

Fig. 6. Dynamical fields from GEOS-5 analyses for August 2007 in subtropical jet coordinates. Top panels show relative vorticity with overlays of windspeed (white), regions with high frequencies of negative latitudinal PV gradients (black), and PV contours of 2, 3, 5, 10, 15, 20 and 30 PVU (magenta). Bottom panels show temperature with overlays of windspeed (white), frequency of high $\left(\geq 4.8 \times 10^{-4} \mathrm{~s}^{-2}\right)$ static stability (black, indicating presence of a TIL, see text), and 2.0 and 6.0 PVU (solid magenta) and WMO (dashed magenta) tropopauses. Greys/purples show low values, oranges/reds high values.

view of conditions surrounding the jets. The relative vorticity fields show the classic picture of cyclonic flow poleward of the jets and anticyclonic flow equatorward of them. Associated with that are very strong PV gradients across the jet; the jet core typically lies between 2.0 and 3.5 PVU, with the strongest gradients (as seen in the spacing of the PV contours) shifting towards higher PV values with increasing altitude, consistent with the results of Kunz et al. (2011). Also shown are contours of the frequency of negative latitudinal PV gradients, commonly used as a diagnostic of Rossby-wave breaking; this highlights regions where wavebreaking is persistent in the same location with respect to the jets. The general features, with regions of negative latitudinal PV gradient near the tropopause (e.g., 3-5 PVU PV contours) at high latitudes in both summer and winter hemispheres, a region above the winter subtropical jet, and regions poleward of the summer subtropical jet, appear consistent 
with previous studies of patterns of Rossby-wave breaking (e.g., Hitchman and Huesmann, 2007). Rossby-wave breaking is associated with meridional transport and ultimately irreversible mixing, so comparison of this diagnostic with trace gas distributions can help improve understanding of the processes controlling those distributions. The negative PV gradient region above the winter subtropical jet is colocated with a bulge in the $36^{\circ} \mathrm{EqL}$ contour seen in Fig. 5, which suggests the possibility of irreversible poleward transport/mixing from this region, as has been reported in previous studies (Rosenlof et al., 1997; Pan et al., 2009; Homeyer et al., 2011, and references therein).

High static stability immediately above the tropopause is associated with the "tropopause inversion layer" (TIL) (Birner, 2006; Randel et al., 2007c; Grise et al., 2010, and references therein). The mechanisms for formation of the TIL have not been determined, but both dynamical processes and radiative effects of $\mathrm{O}_{3}$ and $\mathrm{H}_{2} \mathrm{O}$ variations may be involved (e.g., Randel et al., 2007c; Kunz et al., 2009; Miyazaki et al., 2010a). Observational (Hegglin et al., 2009; Kunz et al., 2009) and model (Miyazaki et al., 2010b) results indicate a relationship between the TIL and processes in the ExTL; the details of this relationship and the role of the TIL in transport and mixing across the tropopause are only beginning to be explored. The lower panels of Fig. 6 show the temperature field in jet coordinates, with overlays of the frequency of static stability greater than a threshold value (chosen based on the work of Grise et al., 2010). These patterns, indicating a strong TIL in the tropics, throughout mid to high latitudes in summer, and (less persistently) in midlatitudes in winter, appear consistent with patterns seen in zonal mean climatologies (e.g., Randel et al., 2007c; Grise et al., 2010).

Figure 7 shows more quantitatively some of the differences between viewing the dynamical fields as a function of $\mathrm{EqL}$ and with respect to the horizontal distance from the subtropical jet. In an average for 11-21 August 2007, the fields at the jet core level are shown as mapped in EqL/ $\theta$ coordinates, with distance from the subtropical jet as a horizontal and $\theta$ as a vertical coordinate, and with distance from the jet as both horizontal and vertical coordinates (as in Figs. 5 and 6). To provide the most direct comparison, EqL values at longitudes that do not have a subtropical jet core identified are excluded from that gridding, so the same longitudes are used for both $\mathrm{EqL}$ and jet-coordinate gridding. The number of points in each bin is shown on the PV panel; because data from the dense GEOS-5 grid are mapped onto a relatively coarse EqL or jet-distance grid, there are typically several hundred to several thousand points in each bin away from the edges of the mapping region. The jet/ $\theta$ coordinate gridding results in fewer points in each bin than the other coordinate combinations, but the fact that the standard deviations for this and the jet/jet coordinate are comparable indicates that the differences in standard deviations are not primarily an artifact of the varying number of points averaged. As expected, the windspeeds are sharply peaked around zero lat-

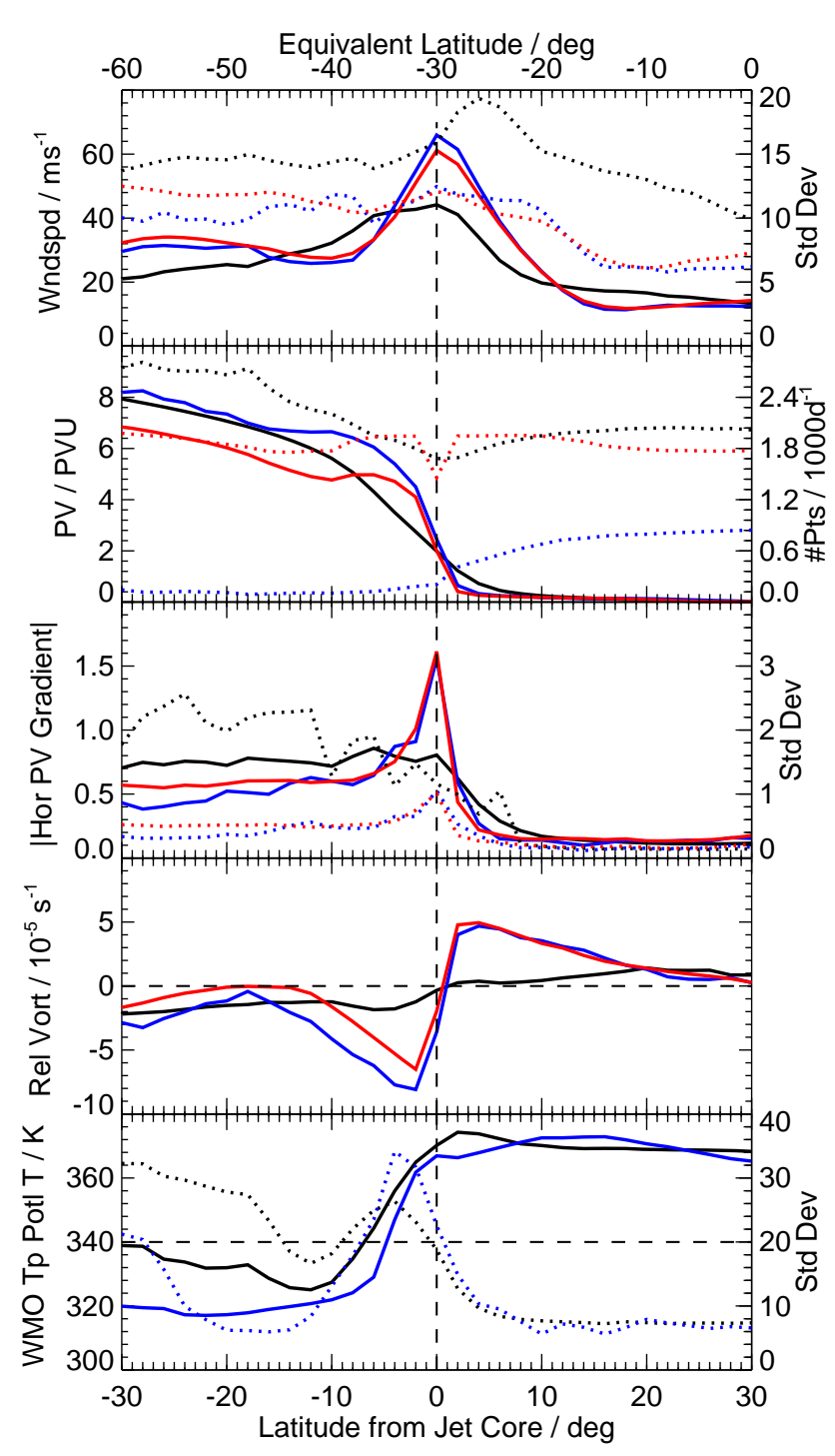

Fig. 7. 11-21 August 2007 GEOS-5 dynamical fields in the $\mathrm{SH}$ at the jet core level $(340 \mathrm{~K}$ for $\theta$ coordinate, the average $\theta$ of the jet during this period) in EqL/ $\theta$ (black; includes only longitudes with a jet core identified), distance from the subtropical jet/ $\theta$ (blue), and jet-distance/jet-distance (red) horizontal/vertical coordinates. Top to bottom: Windspeed, PV, magnitude of the horizontal PV gradient (normalized by the global mean at each $\theta$ level), relative vorticity, and $\theta$ of the WMO tropopause. Standard deviations are shown as dotted lines on windspeed, PV gradient and tropopause $\theta$ panels with ranges given on the right axis. The number of points in each bin for each coordinate combination is shown as a dotted line on the PV panel (second from top) in thousands of points per day. The jetdistance/jet-distance line is not shown on tropopause $\theta$ plot because the units are not comparable. The horizontal axis for the EqL/ $\theta$ fields is drawn so that the average subtropical jet latitude $(\sim-30)$ is aligned with the origin for the jet-distance fields. The horizontal dashed line on the tropopause panel marks the average jet core $\theta$ $(\sim 340 \mathrm{~K})$. 
itude difference, and the standard deviations relatively low (representing the day-to-day variability over the averaging period) for the horizontal jet coordinates. In contrast, the jet maximum in the EqL/ $\theta$ coordinate is broader and much weaker, and standard deviations are much larger, reflecting the fact that not only the strength, but also the location, of the jet varies significantly with time and longitude.

PV values drop sharply across the jet, but in the EqL view, the gradients are more uniform over a broad $\mathrm{EqL}$ range, and drop less abruptly to near-zero equatorward of the jet, indicating that the tropical/subtropical boundary is less clearly defined in the EqL coordinate. By definition, PV is constant around an $\mathrm{EqL}$ contour, so comparison of $\mathrm{PV}$ variability is not meaningful. Consistent with the behavior of the PV field, the horizontal PV gradient has a sharp peak across the jet in the jet coordinate view, but nearly constant, moderate values in the EqL coordinate everywhere poleward of the jet. The standard deviation of the PV gradient is much higher poleward of the jet in the EqL coordinate. These patterns in the PV gradient result from the fact that strongest PV gradients are typically colocated with the jet (Kunz et al., 2011, and references therein), and that PV gradients are much weaker in longitude regions without a strong jet, which are included in the EqL, but not the jet-coordinate, fields. In line with the strong pattern of cyclonic flow poleward of the jet and anticyclonic flow equatorward of it (top panels of Fig. 6), an abrupt change from large negative to large positive values of relative vorticity is seen in jet coordinates across the jet, while in the EqL coordinate, the values are weakly negative poleward of the jet and weakly positive equatorward of it. Standard deviations in this case are comparable for $\mathrm{EqL}$ and jet coordinates (not shown). The tropical tropopause (which does not exhibit large variability) is similar in both coordinate views, and drops only slightly more gradually in the EqL view immediately poleward of the jet, indicating that the transition from tropical to extra-tropical tropopause is fairly well represented in that view. However, poleward of about $-10^{\circ}$ from the jet $\left(-40^{\circ} \mathrm{EqL}\right)$, the tropopause in $\mathrm{EqL}$ coordinates rises and shows much greater variability that that in jet coordinates; this may arise from the influence of regions where the polar jet is dominant and thus the large tropopause drop may occur across that jet (as discussed above in relation to Fig. 5).

The jet coordinate diagnostics thus provide a sharply focused view in relation to the jet of dynamical conditions that are expected to be instrumental in defining the transport characteristics in those regions, and hence in controlling trace gas distributions, in the UTLS. In the next section, we explore how observed trace gas distributions are represented in jetbased and EqL coordinate systems.

\subsection{Trace gas measurements in jet coordinates}

Ray et al. (2004) examined $\mathrm{O}_{3}$ measurements from Winter Storms aircraft missions in relation to the jet (in this case, as with any localized measurements, the closest one to the observations) by using the difference between the windspeed at the measurement location and the maximum windspeed on the same isentropic surface as a horizontal coordinate. In Fig. 8, we show probability density function (PDF) plots of $\mathrm{O}_{3}$ from all Winter Storms flights in January and February of 2002 through 2007. A coordinate similar to that of Ray et al. (2004) is shown by plotting $\mathrm{O}_{3}$ versus the windspeed difference from the jet core for a narrow altitude range $(2 \mathrm{~km}$ below to $2 \mathrm{~km}$ above) around the jet core altitude. This is compared with a plot with the latitude distance from the jet core, derived from our catalog at Winter Storms measurement locations, for the same vertical range. The two jetrelative horizontal coordinates shown quite similar results, as expected since they are different ways of expressing (and "stretching") the distance from the jets; they also strongly resemble the winter PDFs shown by Ray et al. (2004, see Fig. 3) for flights in 2001, 2002 and 2003, for the 320-340 K and $340-360 \mathrm{~K}$ ranges (the average jet core potential temperature for the flights shown here is $\sim 330 \mathrm{~K}$, with a range from $\sim 320$ to $360 \mathrm{~K}$ ). The $\mathrm{O}_{3}$ increase across the jet is not as sharp (especially in the top panel) as their winter case, most likely resulting primarily from interannual differences in both sampling and meteorological conditions. Using the data in a $4 \mathrm{~km}$ altitude bin centered on the jet core includes data up to about $370 \mathrm{~K}$, so maximum and mean $\mathrm{O}_{3}$ values poleward of the jet are overall higher than those shown by Ray et al. (2004). When larger or smaller altitude ranges are used (e.g., a $3-\mathrm{km}$ or a $6-\mathrm{km}$ wide bin), the sharpness of the $\mathrm{O}_{3}$ increase across the jet division remains similar, indicating that the jets are not, on average, strongly tilted with height, and that the jet core position is relevant to the $\mathrm{O}_{3}$ distribution over a significant altitude range.

Figure 8 also shows the complete data from the January/February 2002-2007 Winter Storms flights mapped in latitude and altitude from the nearest jet core. Very sharp horizontal $\mathrm{O}_{3}$ gradients are seen across the jet core latitude from about $1 \mathrm{~km}$ below to $3 \mathrm{~km}$ above the jet core, with weaker, but still strong gradients $1-3 \mathrm{~km}$ below and above this range. The strongest $\mathrm{O}_{3}$ gradients are generally slightly below the position of the tropopause overlaid, suggesting that for the conditions of these flights, the 4.5 PVU tropopause shown here is slightly higher than the strongest transport barrier. The strong ozone gradients across the origin in jet coordinates are in accord with the role of the jets as a transport barrier. Higher $\mathrm{O}_{3}$ well below the tropopause poleward and below the jet (as well as equatorward of and above the jet) suggests stratospheric intrusions, consistent with the common occurrence of tropopause folds in this region. Regions of low $\mathrm{O}_{3}$ poleward of the jet above the tropopause suggest tropospheric intrusions (e.g., $\sim 5^{\circ}$ poleward of and $1.5 \mathrm{~km}$ above, and $\sim 15^{\circ}$ poleward of at the jet core altitude); while somewhat noisy because of the sampling, the $\mathrm{O}_{3}$ changes in and spatial extent of these features significantly exceed the precision and resolution of the measurements. A suggestion of higher ozone at $\sim 4-6 \mathrm{~km}$ above and $16-20^{\circ}$ poleward of 

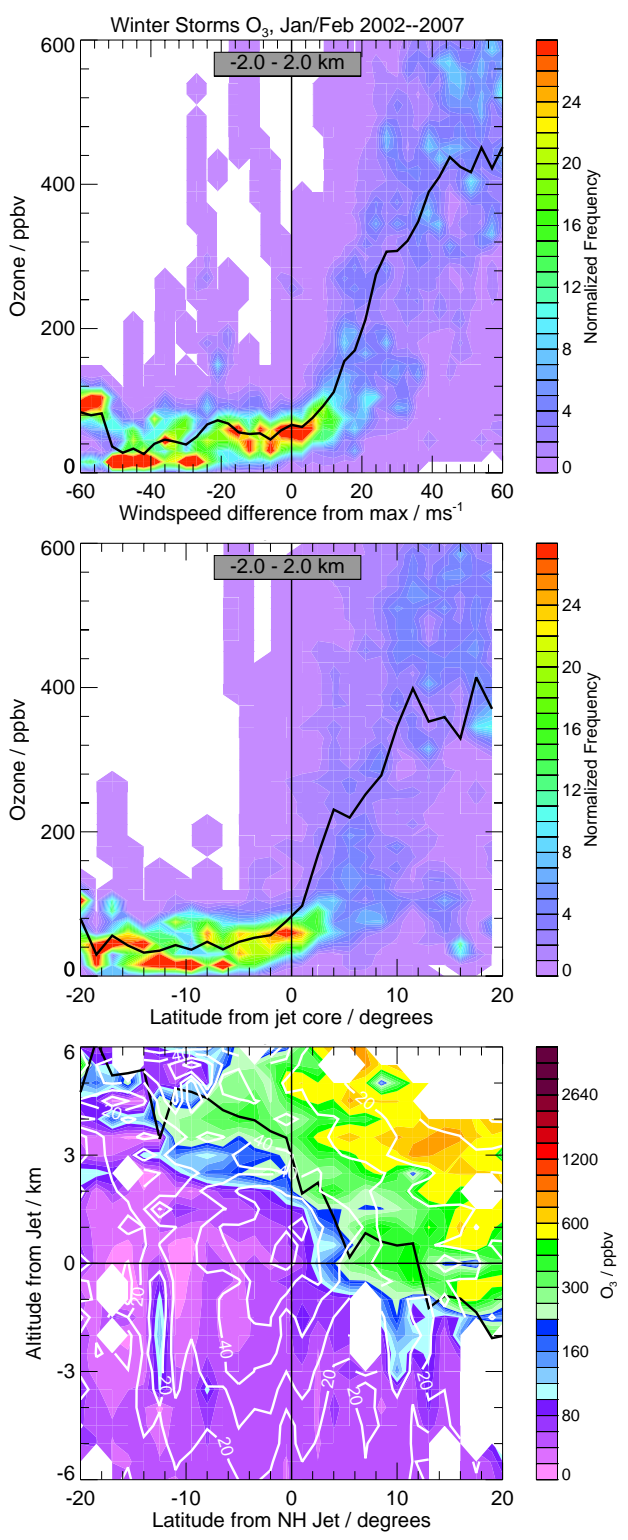

Fig. 8. $\mathrm{O}_{3}$ data from all Winter Storms flights in January and February 2002 through 2007. (Top) $\mathrm{O}_{3}$ PDF for data from $2 \mathrm{~km}$ below to $2 \mathrm{~km}$ above the jet with windspeed difference from the jet core maximum windspeed as the horizontal coordinate (negative values indicate measurements equatorward of the jet, positive values measurements poleward of the jet). (Center) a similar PDF but with latitude distance from the jet core as the horizontal coordinate. PDFs are normalized by the total number of points in each horizontal bin, giving the probability of a particular ozone mixing ratio in that bin, following Ray et al. (2004). (Bottom) $\mathrm{All} \mathrm{O}_{3}$ mixing ratio data from these flights gridded with latitude distance from the jet core as the horizontal coordinate and altitude distance from the jet core as the vertical coordinate; white overlays are GEOS-5 windspeeds at the measurement locations; black overlay shows average tropopause at the measurement locations in each horizontal bin. Purples show low values, oranges/reds high values. the jet core may arise from data taken in a situation where the jet is highly distorted such that it does not approximate east/west flow. In such cases, the identification of the jet in longitude slices is inadequate to describe the relationship of the measurements to the circulation. Our jet characterization method can be easily adapted to identify the jet cores along other slices, such as a perpendicular from the measurement to the nearest jet - such a view will be useful for more detailed studies of localized datasets.

One of the primary motivations of this work is to devise ways of analyzing satellite measurements to maximize extraction of information on UTLS processes and trace gas distributions from these comprehensive (global, multi-annual coverage) but relatively low-resolution datasets. For development of these methods we focus first on the EOS Aura MLS measurements. While MLS UTLS measurements have been validated and shown to characterize the morphology of the distributions of several trace gases well in that region (Livesey et al., 2008), the vertical resolution is nominally $2.5-4 \mathrm{~km}$, so it is fair to question whether they have the information content to be useful in many UTLS studies. Figure 9 shows a "curtain plot" of $\mathrm{O}_{3}$ along the $\mathrm{NH}$ portion of one MLS orbit track over North America on 9 May 2008; the profiles are plotted with no horizontal interpolation, but are interpolated from the native pressure levels to use distance (in altitude) from the 4.5 PVU tropopause as a vertical coordinate to highlight the behavior near the tropopause. The large-scale features of the $\mathrm{O}_{3}$ distribution are clearly shown, with very strong, uniform gradients above the tropopause in the tropics and much weaker and more variable gradients in the ExTL; the strong, uniform tropical gradients are consistent with the results of Hegglin et al. (2009) showing strongest $\mathrm{O}_{3}$ gradients in the first $\sim 4 \mathrm{~km}$ above the tropical tropopause. This figure also suggests that MLS is seeing evidence of stratospheric air intruding into the troposphere (e.g., higher $\mathrm{O}_{3}$ values below the WMO tropopause "break", the discontinuity seen in the solid red contour near the jet core; and higher values equatorward of the jet out to $\sim 15^{\circ} \mathrm{N}$ ). There is a clear example of a pocket of much lower $\mathrm{O}_{3}$ in the stratosphere, just above $380 \mathrm{~K}$ near $70^{\circ} \mathrm{N}$; this suggests transport of low-latitude air (possibly from the upper troposphere) with lower $\mathrm{O}_{3}$ well into the stratosphere. During many of the flights in the Stratosphere-Troposphere Analyses of Regional Transport 2008 (START08) campaign (Pan et al., 2010), tropospheric intrusions (layers of tropospheric air, diagnosed by trace gas values and meteorological information, at high altitude sandwiched between layers with stratospheric characteristics) were sampled. Evidence from the START08 measurements during the flight on 9 May 2008 (the day of the MLS data shown in Fig. 9) indicates that lower $\mathrm{O}_{3}$ air in the stratosphere originated in the subtropical troposphere (Homeyer et al., 2011). The low ozone observed on this orbit by MLS has values higher than typical of tropospheric air; thus it may represent transport of low-latitude air from near the tropopause, it could be a signature of a 


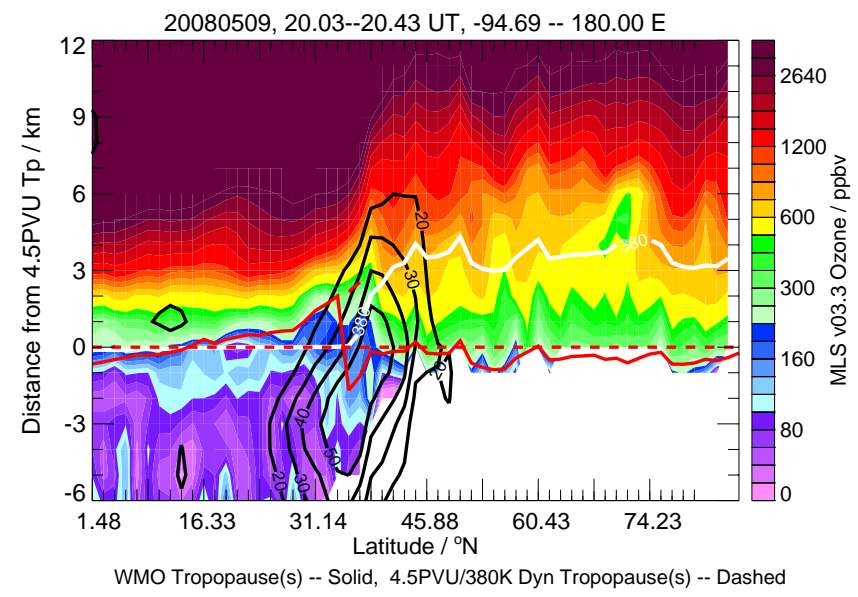

Fig. 9. MLS v3.3 $\mathrm{O}_{3}$ along the $\mathrm{NH}$ section of one orbit track on 9 May 2008 over North America. Horizontal coordinate is the profile number along the orbit track, with a major or minor tick at each profile location, and labeled with the latitude of every 10th profile. The vertical coordinate is distance in altitude from the 4.5 PVU tropopause (identified in GEOS-5 data interpolated horizontally to the profile locations, with altitudes derived from GEOS-5 geopotential heights used for the interpolation). Windspeed contours of $20,30,40$ and $50 \mathrm{~ms}^{-1}$ are overlaid in black. The solid red contour is the WMO tropopause (dashed red is the 4.5 PVU tropopause, or zero, line), and the thick white contour is $380 \mathrm{~K}$ potential temperature. Purples show low values, reds/browns high values.

tropospheric intrusion smeared out by the vertical interpolation and/or MLS vertical resolution, or may be air from an earlier tropospheric intrusion that has subsequently experienced some mixing. In any case, it nevertheless represents distinct relatively small scale structure observed by MLS. Similar features are common in the MLS data and when over North America generally appear consistent with conditions observed during START08 flights. Manney et al. (2009b) also showed examples of stratospheric and tropospheric intrusions captured in MLS orbit curtain plots.

Examination of individual MLS profiles thus demonstrates that many interesting relatively localized features of UTLS trace gas distributions are captured in MLS trace gas data. These data are also well-suited to exploring geographic and temporal variability and climatology of the large-scale trace gas distributions in the UTLS region if we can highlight their relationships to UTLS circulation features. In Figs. 10 through 12 we show MLS $\mathrm{O}_{3}$ data from 9 May 2008 (the same day as the orbit section shown in Fig. 9) with several combinations of vertical and horizontal coordinates. Figure 10 shows the data from 9 May 2008 (both weak and strong jet regions) plotted with $\mathrm{EqL}$ as the horizontal coordinate and $\theta$ as the vertical coordinate, gridded separately for the points at longitudes with and without subtropical jet cores; Fig. 11 uses the EqL horizontal coordinate (for all measurements) with distance from the 4.5 PVU tropopause expressed in $\theta$ and in altitude as the vertical coordinate. Figure 12 shows the data using the latitude distance from the subtropical jet as the horizontal coordinate, and vertical coordinates of distance in altitude from the 4.5 PVU dynamical tropopause and distance in altitude from the subtropical jet core. The latter view is shown both with all data and with data limited to $220-310^{\circ} \mathrm{E}$ longitudes (over the extended North American region in the $\mathrm{NH}$ ). Note that some of the differences in smoothness may arise from the difficulty in selecting bin sizes that are comparable in different coordinate systems. It is important to keep in mind that using the jet as a horizontal coordinate is not simply a matter of rotating and/or distorting the space in which the data are plotted: because the upper tropospheric jets are not continuous around the globe, the jet coordinate view not only aligns the data with respect to the jet location, but also focuses in on the subset of the data in longitude regions where there is a well-defined jet. In all coordinate systems, most of the filled bins away from the edges of the region covered have from about five to over 50 points; the smaller numbers are seen at low latitudes ( 0 to $20^{\circ} \mathrm{EqL}$ or 10 to $30^{\circ}$ equatorward of the jet), lowest levels in the altitude coordinates (below $\sim 6 \mathrm{~km}$ below the jet or tropopause), and highest levels in $\theta$ coordinates (above $\sim 380 \mathrm{~K}$ ). Outside of those sparser regions, the various coordinate combinations have comparable numbers of points in each bin.

The EqL-coordinate plots in Figs. 10 and 11 show clearly the strong vertical gradients across the tropopause, and also show fairly strong horizontal gradients across the region of the jet, consistent with previous UTLS studies using these coordinates (e.g., Hoor et al., 2004; Hegglin et al., 2006). The patterns seen in the top panels, for strong jet regions, are, on this day, very similar to those obtained when all data are gridded together (probably largely because the majority of longitudes sampled have a subtropical jet core). The bottom panels, for weak jet regions, show areas, especially along the top of the jet in each hemisphere, with significantly lower $\mathrm{O}_{3}$ above the tropopause than in the strong jet case, as well as significantly higher $\mathrm{O}_{3}$ values below the $\mathrm{NH}$ jet and tropopause. This is consistent with the expectation of a lesser transport barrier associated with weaker jets, and shows how the jet catalog can be used to contrast transport in strong and weak jet regions.

Both of the tropopause vertical coordinates, expressed in $\theta$ or altitude, highlight the evidence for stratospheric intrusions in the vicinity of the jets (higher $\mathrm{O}_{3}$ values extending well below the tropopause), though the altitude coordinate plots highlight the extent of these features and the strong vertical gradients more clearly. Consistent with the results of Hoor et al. (2004) and the latitudinal variations in the thermal structure of the atmosphere, vertical $\mathrm{O}_{3}$ gradients relative to the tropopause are much more uniform with latitude when expressed in $\theta$ (bottom panel of Fig. 11). Thus, as noted by Hegglin et al. (2009), expressing the distance from 

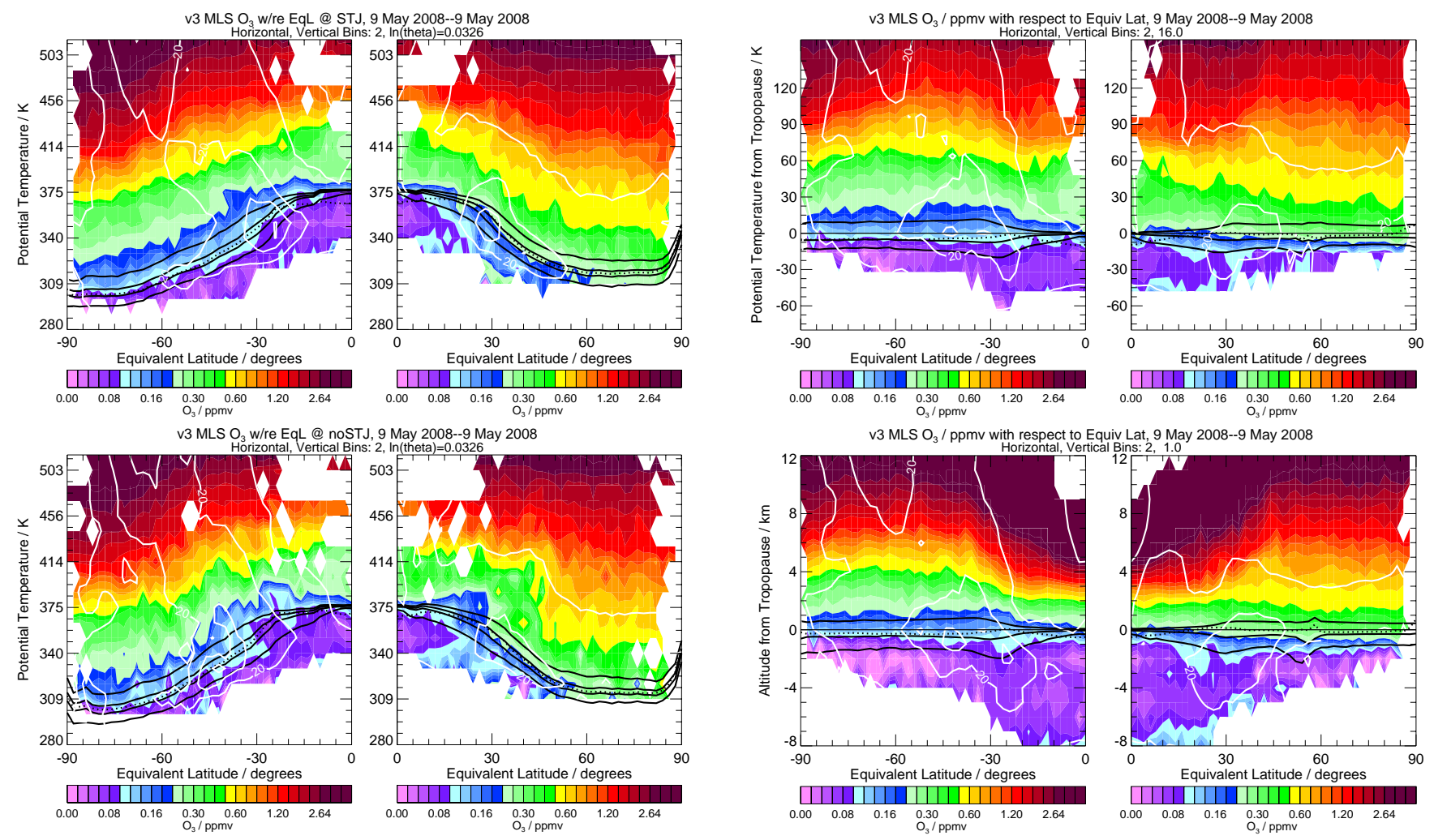

Fig. 10. MLS v3.3 $\mathrm{O}_{3}$ data on 9 May 2008 plotted as a function of EqL and $\theta$, gridded for (top) all measurements at longitudes where a subtropical jet core was identified, and (bottom) all measurements at longitudes where there was no subtropical jet core. White overlays are GEOS-5 windspeeds, black overlays 2.0, 3.5, 4.5 and 6.0 PVU dynamical (solid lines) and WMO (dotted line) primary tropopause locations from GEOS-5. Thin black line marks zero. The data were binned and averaged on a $2^{\circ} \mathrm{EqL}$ grid, with 20 levels equally spaced in $\ln (\theta)$ between 280 and $520 \mathrm{~K}$. Purples show low values, reds/browns high values.

the tropopause in altitude or $\theta$ provides a different perspective on the latitudinal variations in trace gas gradients in the ExTL.

It is apparent when comparing Figs. 10 and 11 with 12 that the EqL coordinate does not fully capture either the relationship between the $\mathrm{O}_{3}$ distribution and the jets or the characteristics of the jets themselves. The subtropical jet is ill-defined in the windspeed contours in the top panels of Fig. 10 (which include the same points as the jet-coordinate plots). The slope of the tropopause contours across the jet region is also much more gradual in EqL than in jet coordinates. The association of the strongest PV gradients with the jet core (extending from $\sim 2 \mathrm{~km}$ below to $\sim 4 \mathrm{~km}$ above the jet core) is clearly defined in the jet/jet coordinate (center) panel of Fig. 12. These differences are consistent with the patterns shown in Fig. 7. Consistent with the results of Kunz et al. (2011), the dynamical tropopause contours indi-

Fig. 11. All MLS v3.3 $\mathrm{O}_{3}$ data on 9 May 2008 plotted as a function of EqL and distance in $\theta$ from the 4.5 PVU tropopause (top), and EqL and distance in altitude from the 4.5 PVU tropopause (bottom). Overlays are as in Fig. 10. The data were binned and averaged on a $2^{\circ}$ EqL by $2 \mathrm{~km}$ altitude grid. Purples show low values, reds/browns high values.

cate a shift in the strongest gradients, and in the contour that aligns most closely with the jet core, from below to above the jet: $\sim 2-0 \mathrm{~km}$ below the jet, the strongest PV gradients are near the lowest (2 PVU) contour shown, and that contour sits at the latitude of the jet core; $\sim 2-4 \mathrm{~km}$ above the jet, the 4.5 to $6.0 \mathrm{PVU}$ contours align with the jet core latitude and strongest PV gradients are shifted towards those values. The changing gradients in $\mathrm{MLS} \mathrm{O}_{3}$, and the shift in location of tropospheric versus stratospheric values, closely follow the changes in PV gradients, supporting the supposition that these changes - closely dynamically linked in PV and jet structure - control the strength of the transport barrier across the jet and tropopause break.

While the extension of higher $\mathrm{O}_{3}$ (values between 100 and 200 ppbv) downward across the tropopause near the NH subtropical jet can be seen in all views shown here, only the jet coordinate views in Fig. 12 clarify its location to be primarily poleward of the jet. The EqL coordinate view confirms that this is associated with irreversible stratosphere to troposphere transport. The jet/jet coordinate plots (Fig. 12, center) highlight even higher (up to $\sim 300 \mathrm{ppbv}$ ) values extending into the 

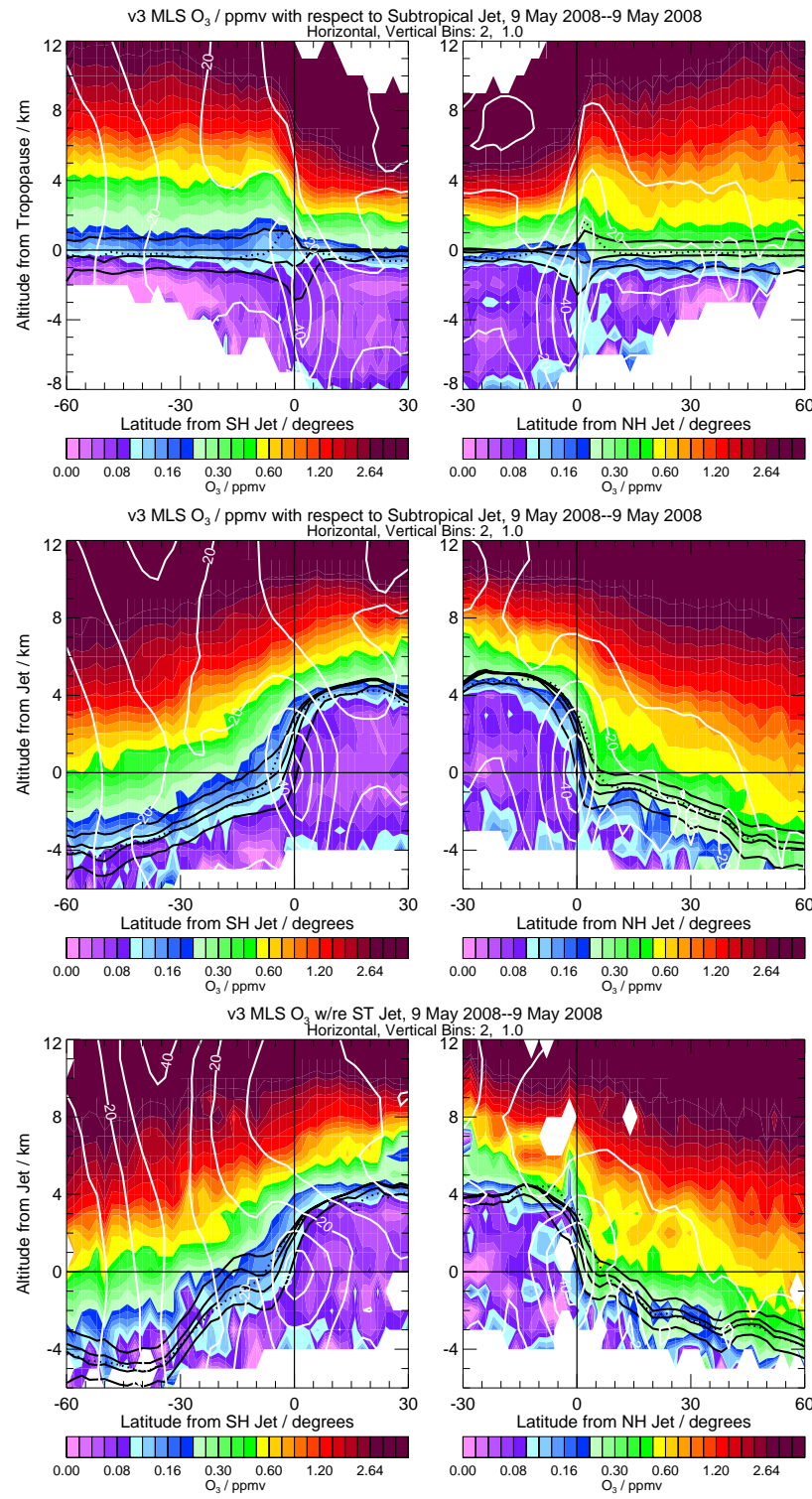

Fig. 12. As in Fig. 10 but with distance from the subtropical jet as the horizontal coordinate. Top plot has altitude distance from the 4.5 PVU tropopause as the vertical coordinate; center and bottom plots have altitude distance from the subtropical jet core as the vertical coordinate. The bottom panel is gridded only from data between $220^{\circ} \mathrm{E}$ and $310^{\circ} \mathrm{E}$ longitude. The data were binned and averaged on a $2^{\circ}$ latitude by $2 \mathrm{~km}$ altitude grid. Purples shows low values, reds/browns high values.

tropopause region, especially $\sim 5-10^{\circ}$ poleward of the jet and near $30^{\circ}$ poleward of the jet. Interestingly, the $\mathrm{SH}$ jet/jet coordinate plots also suggests poleward transport across the top of the subtropical jet (the "kink" 2-4 km above the jet core near $15-20^{\circ}$ poleward of the jet) that is not obvious in any of the other views of strong jet regions, but resembles the patterns seen in the EqL/ $\theta$ coordinate view of weak jet regions; this suggests that this type of transport might also occur in strong jet conditions but not be apparent in the EqL view because the data showing it are not "focused" into the same bins, and because the strength of the jet also varies within those regions (note that the feature is more prominent in the longitude-limited plot over the extended North American region, which also has a slightly weaker jet than the global average).

The jet/jet coordinate plot limited to the extended North American region shows substantially more evidence of local cross-tropopause exchange in both directions in the NH. These are generally robust features in the MLS data and those in the NH are consistent with the conditions observed during the START08 campaign at this time. In particular, there are several places in the region from the jet core to $\sim 30^{\circ}$ poleward of it where lower $\mathrm{O}_{3}$ values are sandwiched in between higher ones, both above the tropopause and in the tropopause region. Results from the START08 campaign show evidence for extensive regions with tropospheric air sandwiched between layers of stratospheric air, indicative of tropospheric intrusions (e.g., Pan et al., 2010; Homeyer et al., 2011), including during the flight on the date shown here. The regions of $\mathrm{O}_{3}$ near or above $300 \mathrm{ppbv}$ below the tropopause poleward of the jet core are more extensive when focusing on the extended North American region, and an indication of higher $\mathrm{O}_{3}$ extending below the tropopause is apparent equatorward of and above the jet core in the $\mathrm{NH}$, near $10-20^{\circ}$ equatorward of the jet. The feature in the $\mathrm{SH}$ suggesting poleward transport across the top of the jet is accentuated as well. A localized region of very low $\mathrm{O}_{3}$ is seen above the tropical tropopause in both hemispheres. Examination of maps, curtain plots, and individual tropical $\mathrm{O}_{3}$ profiles on this day shows the $\mathrm{SH}$ feature to be a robust one spanning several profiles with physically realistic appearing variations. Jet coordinate plots indicate such a feature is persistent through much of May 2008. A vertically-localized region of low $\mathrm{O}_{3}$ above the tropical tropopause that appears consistent with this has previously been reported by Randel et al. (2007a).

As noted in Sect. 4.2, the polar jet is washed out in these plots with respect to the subtropical jets, indicating (as expected from the climatology of the jets, e.g., Sect. 4.1) substantially different longitudinal distributions and the decreasing influence of the subtropical jet on the flow at more distant latitudes. Numerous criteria may be used to select which jets to composite, not only the simple division by latitude of the subtropical and polar jets considered here, but also such distinctions as the the lowest latitude jet, regardless of absolute latitude (to include cases such as very strong blocking events where the strong jet across which the tropopause "breaks" is shifted to high latitude) or the jet closest to the measurement locations (as done for Winter Storms data above; to highlight the jet that is the strongest influence on localized measurements).

The above figures showing various coordinate views of MLS data clearly highlight advantages of using the jet as 

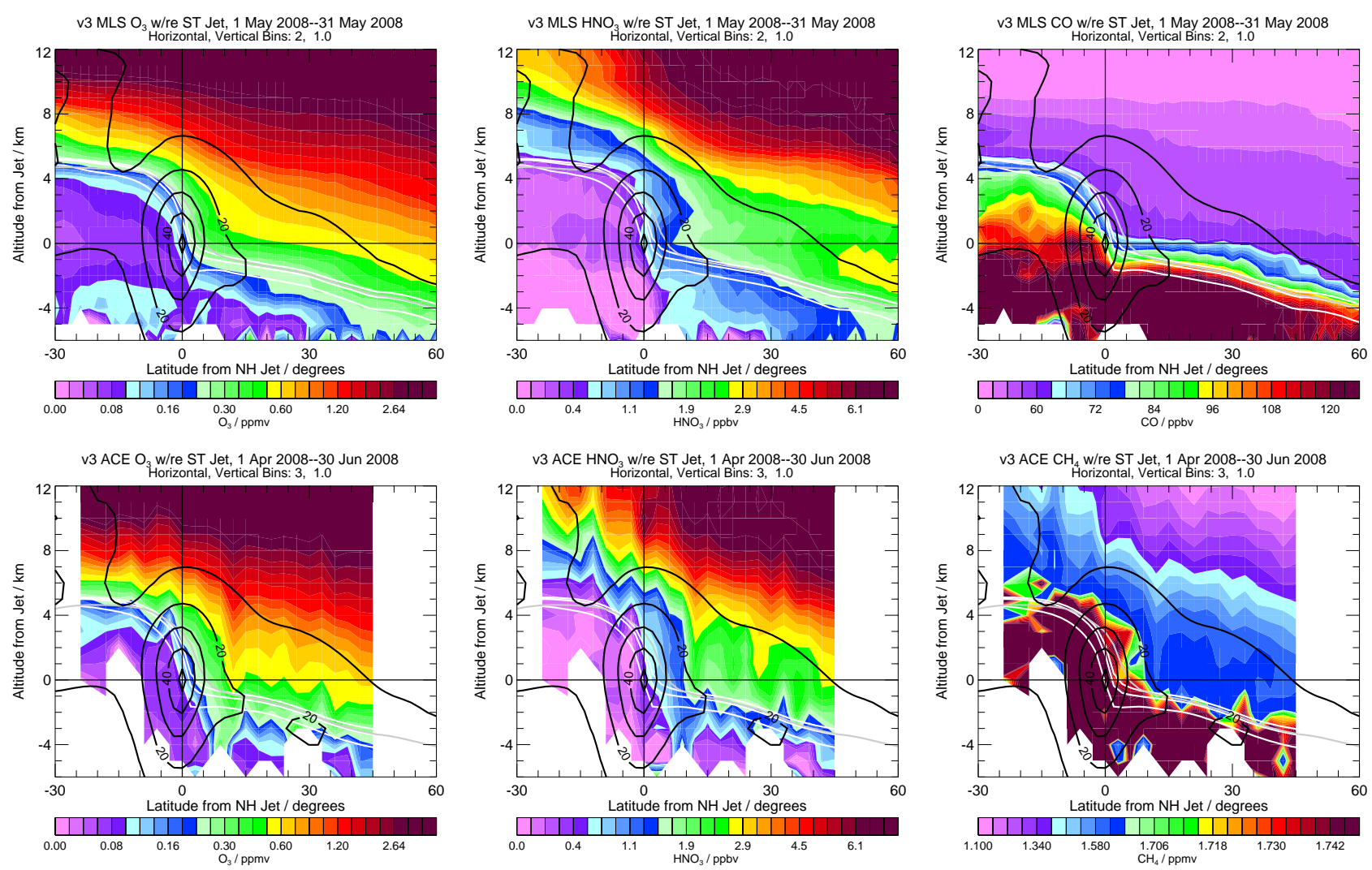

Fig. 13. Climatological plots from MLS and ACE-FTS data in jet coordinates. Top row shows (left to right) $\mathrm{MLS}^{\mathrm{v}} 3.3 \mathrm{O}_{3}, \mathrm{HNO}_{3}$, and $\mathrm{CO}$ during May 2008. Bottom row shows ACE-FTS v3.0 $\mathrm{O}_{3}, \mathrm{HNO}_{3}$ and $\mathrm{CH}_{4}$ during April through June 2008. Black overlays are GEOS-5 windspeeds, white overlays are 2.0, 3.5 and 4.5 PVU primary tropopauses, and grey line is the WMO tropopause. Purples show low values, reds/browns high values.

a horizontal coordinate, for example, in providing a previously unavailable picture of the strength of and relationships between $\mathrm{PV}$ and $\mathrm{O}_{3}$ gradients across the jet. With the jet also used as a vertical coordinate, we can focus clearly on the relationships of the dynamical variations accompanying the upper tropospheric jets (e.g., winds, PV gradients and tropopauses) to the trace gas distributions. For some studies, the combination of a jet coordinate in the horizontal with a tropopause-relative vertical coordinate may also provide valuable information, e.g., for assessing the relative gradients across the tropopause as a function of time and location while retaining a focus on the role of the jets.

The methods described above are being used to develop a jet-relative climatology of trace gases. Figure 13 shows examples of monthly/seasonal mean (May 2008 for MLS and April-June 2008 for ACE-FTS, both during the START08 aircraft campaign) satellite-measured trace gas fields in subtropical jet coordinates. The $\mathrm{O}_{3}$ and $\mathrm{HNO}_{3}$ fields from MLS and ACE-FTS show good agreement, even in features that might otherwise be considered dubious, such as the slightly higher $\mathrm{HNO}_{3}$ extending equatorward at jet core level, and the indications of intrusion of stratospheric values below the tropopause just poleward of the jet. Thus, the jet coordinate also provides a useful framework for comparing UTLS measurements that are not geographically coincident. The stratospheric intrusions hinted at in the stratospheric tracers $\mathrm{O}_{3}$ and $\mathrm{HNO}_{3}$ are not as obvious in the tropospheric tracers $\mathrm{CO}$ (shown from MLS; ACE-FTS CO is consistent) and $\mathrm{CH}_{4}$ (measured by ACE-FTS), though there is a dip in the values at the kink in the tropopause; the extremely strong gradients in these tracers lead to very high tropospheric values in which the dilution by localized injection of low stratospheric values may not result in an obvious change. This emphasizes the value of examining multiple tracers; in addition to those shown here, both MLS and ACE-FTS measure $\mathrm{HCl}$ and $\mathrm{H}_{2} \mathrm{O}$ extending into the UTLS, and ACE-FTS measures numerous other tracers.

Figure 13 shows more small-scale structure in the ACEFTS plots compared to the MLS panels. This is to a large degree related to the sparser ACE-FTS sampling (a factor of over 10 each day, so still very significant in three months for ACE-FTS versus one month for MLS). However, atmospheric features may also be captured by only one of the two instruments not only because of different sampling in the 
horizontal, but also because of vertical sampling and resolution differences. ACE-FTS has been shown to often achieve an effective vertical resolution near $1 \mathrm{~km}$ in the UTLS (Hegglin et al., 2008); while the ability of MLS to resolve smallvertical-scale features has yet to be explored in detail, Fig. 9 and the accompanying discussion suggest that it does capture variability on scales that might not be obvious given the nominal resolution. The jet coordinate and jet/tropopause coordinate views are being used to help explore the degree to which such structures are represented in MLS data.

A climatology of MLS and ACE tracers in jet coordinates covering each entire mission is being used to explore the seasonal and interannual variations of UTLS trace gas distributions, and will be viewed in conjunction with the climatology of dynamical fields such as those shown in Figs. 6 to diagnose underlying processes causing those variations.

\section{Discussion}

A simple method has been developed to classify the UTLS jets, both the upper tropospheric jets and the subvortex jet (the lowest extension of the stratospheric polar night jet). The parameters used have been tuned in an attempt to approximate as closely as possible what the human eye would tell us were we able to examine and identify each jet visually. Information about the dynamical/thermal environment (e.g., winds, temperature, relative and potential vorticity) is cataloged along with the locations of the jet cores and edges of the jet regions.

Accompanying the catalog of jet locations and dynamical characteristics is a detailed catalog of tropopause information, including locations of the thermal (WMO) tropopause and dynamical tropopauses defined using several PV values. The catalog includes multiple (double and triple) tropopauses. Distances from the tropopauses are included in the jet catalogs. The first jet and tropopause catalogs we have developed and tested are from the GEOS-5 (MERRA reanalysis and GEOS-5 operational) meteorological fields.

The jet characterization is motivated largely by the desire to develop tools tailored to studying the extensive global satellite measurements that have become available in the UTLS in the last several years, and to relating those broadbrush measurements to the detailed, but localized (in space and time), views provided by aircraft and ground-based data. To this end, we have also cataloged the relationships of MLS and ACE satellite measurement locations and dynamical environments to the jet locations and characteristics. Such catalogs have also been developed for several aircraft projects, including the Winter Storms campaigns in 2002 through 2007.

Meteorological fields and trace gas data are being mapped using the jet core locations as a coordinate system. The jetfocused view goes beyond a simple coordinate transformation in that it focuses attention only on regions where there are well-defined jets, facilitating study of the relationships of dynamical fields and trace gas distributions to jet characteristics by focusing on regions influenced strongly by a jet. Examples of $\mathrm{EqL}$ and potential temperature mapped in jet coordinates demonstrated that, even in the vicinity of jets where EqL shows very strong horizontal gradients, the jet coordinate provides a different view of the dynamical fields than does $\mathrm{EqL}$ at altitudes throughout lowermost stratosphere and in the upper troposphere in the latitude regions influenced by the jets. Mapping dynamical fields, such as PV, static stability, and others, in jet coordinates provides a focus on their relationships to jet structure and evolution. On the other hand, a dynamical coordinate mapping in $\mathrm{EqL}$ space can change the relative distances between points, thus obscuring spatial relationships, but provides information on where PV conservation may not hold.

The view of UTLS MLS $\mathrm{O}_{3}$ data is compared using EqL and distance from the subtropical jet as horizontal coordinates in combination with several vertical coordinates. While both views show evidence of STE in the existence of $\mathrm{O}_{3}$ values characteristic of the stratosphere well below the tropopause, the EqL/ $\theta$ view blurs the representation of the jet and the strong gradients (in PV, tropopause altitude, and $\mathrm{O}_{3}$ ) crossing the jet core, and thus the relationship of that STE to the jets; the jet-coordinate view shows that stratospheric $\mathrm{O}_{3}$ values in the troposphere are concentrated poleward of and below the jets. It is the EqL coordinate view, however, that confirms that the apparent signatures of STE represent irreversible transport. The view using the subtropical jet core as both horizontal and vertical coordinates highlights the correlation between strong PV and tropopause height gradients and very strong $\mathrm{O}_{3}$ gradients. Vertical coordinates relative to the tropopause are also valuable, especially in defining the strong trace gas gradients across the tropopause. For studies such as quantifying the geographic and temporal variability of large-scale trace-gas gradients across the tropopause, it may prove valuable to examine both tropopause- and jetrelative vertical coordinates in combination with the horizontal jet coordinate, as well as using the EqL/tropopause framework to obtain a global picture.

\section{Conclusions and ongoing work}

The overall jet catalog is being used to develop a climatology of the upper tropospheric and subvortex jet characteristics and evolution and their relationships to the tropopause (Manney et al., 2011). Examples presented here show well known features of the upper tropospheric jet structure: the high altitude $(\sim 11-14 \mathrm{~km})$ subtropical jet and lower $(\sim 8-$ $11 \mathrm{~km}$ ) altitude polar jet, with a strong drop ("break") in the tropopause across the subtropical jet. Other features are consistent with previous studies of jet climatology and evolution: There is commonly a concentric pattern of polar and subtropical jets in the $\mathrm{SH}$, with the polar jet frequently being the stronger one in summer. The $\mathrm{NH}$ winter jet patterns show 
persistent excursions of the primary jet to high latitudes associated with strong (blocking) ridges, sometimes associated with forcing of stratospheric sudden warmings. More frequent jets in a region are also associated with stronger average jet windspeeds. These and other climatological features of the jets are being compared with satellite-observed trace gas characteristics and mixing diagnostics to help understand the jets' influence on transport.

A jet-coordinate view of Winter Storms aircraft data shows statistical relationships to the jet consistent with a previous study, and highlights strong $\mathrm{O}_{3}$ gradients across the jet and evidence of stratospheric intrusions. In addition to defining the locations of stratospheric and tropospheric intrusions with respect to the jets, MLS data mapped in jet coordinates also highlight evidence for poleward transport across the top of the subtropical jet. MLS and ACE-FTS trace gas data agree well when using jet coordinates to compare non-coincident data, and show evidence of the preferred regions for stratospheric intrusions in monthly or seasonal mean fields. A comprehensive climatology in jet coordinates is being developed from these satellite datasets.

The procedures we have developed to characterize the UTLS jets and the tropopause region have been shown to capture previously reported climatological features of jet distributions and evolution, and will facilitate comparison of jet and tropopause evolution to satellite trace gas climatologies. In addition to the MLS and ACE-FTS jet-relative climatologies described above, we are in the process of cataloging jet and tropopause information for the Aura HIRDLS satellite dataset, and the START08 and SPURT (Engel et al., 2006) aircraft campaigns. HIRDLS data, though more limited in time (late 2004 through early 2008), will provide a valuable addition to the satellite climatologies because of their good vertical resolution. The jet-coordinate view of START08 data is being used as part of a detailed study comparing START08 with MLS data and using analyses of MLS data to provide hemispheric context for the regional START08 measurements.

The development of the jet classification scheme and its application to analyses in jet-relative coordinates provide a wealth of opportunities for more focused studies of the extensive UTLS trace gas data that are becoming available and will facilitate many analyses pertinent to understanding climate change and upper tropospheric pollution transport. We are working on packaging the jet and tropopause catalogs at measurement locations for eventual public release.

Acknowledgements. Thanks to the MLS team (especially Ryan Fuller, Brian W. Knosp, Brian J. Mills, and Robert P. Thurstans) and the ACE Team (especially Sean McLeod and Ryan Hughes) for their continuing support and assistance. Thanks to NASA's GMAO for providing their assimilated data products. Thanks to Kirstin Krüger, Karen Rosenlof, Irina Petropavlovskikh, Dylan Jones, Ken Minschwaner, Michael Sigmond, Laura Pan, Cameron Homeyer and Ted Shepherd for many valuable discussions, and to the two anonymous reviewers for helpful comments. Research at the Jet Propulsion Laboratory, California Institute of Technology (JPL/Caltech), was done under contract with the National Aeronautics and Space Administration. The lead author's copyright for this publication is transferred to JPL/Caltech. Funding for the ACE mission was provided primarily by the Canadian Space Agency (CSA) and the Natural Sciences and Engineering Research Council of Canada. MIH has been supported by the Canadian Foundation for Climate and Atmospheric Sciences and the CSA through the C-SPARC network.

Edited by: W. Lahoz

\section{References}

Archer, C. L. and Caldeira, K.: Historical Trends in the Jet Streams, Geophys. Res. Lett., 35, L08803, doi:10.1029/2008GL033 614, 2008.

Bernath, P. F., McElroy, C. T., Abrams, M. C., Boone, C. D., Butler, M., Camy-Peyret, C.,Carleer, M., Clerbaux, C., Coheur, P.-F., Colin, R., DeCola, P., DeMaziere, M., Drummond, J. R., Dufour, D., Evans, W.F.J., Fast, H., Fussen, D., Gilbert, K., Jennings, D. E., Llewellyn, E. J., Lowe, R. P., Mahieu, E., McConnell, J. C., McHugh, M.,McLeod, S. D., Michaud, R., Midwinter, C., Nassar, R., Nichitiu, F., Nowlan, C., Rinsland, C. P., Rochon, Y. J., Rowlands, N., Semeniuk, K., Simon, P., Skelton, R., Sloan, J. J., Soucy, M.-A., Strong, K., Tremblay, P., Turnbull, D. ,Walke, K. A., Walkty, I., Wardle, D. A., Wehrle, V., Zander, R., and J.Zou: Atmospheric Chemistry Experiment (ACE): mission overview, Geophys. Res. Lett., 32, L15S01, doi:10.1029/2005GL022386, 2005.

Birner, T.: Fine-scale structure of the extratropical tropopause region, J. Geophys. Res., 111, D04104, doi:10.1029/2005JD006 301, 2006.

Bloom, S. C., Takacs, L. L., da Silva, A. M., and Ledvina, D.: Data Assimilation Using Incremental Analysis Updates, Mon. Weather Rev., 124, 1256-1271, 1996.

Boone, C. D., Nassar, R., Walker, K. A., Rochon, Y., McLeod, S. D., Rinsland, C. P., and Bernath, P. F.: Retrievals for the Atmospheric Chemistry Experiment Fourier-Transform Spectrometer, Appl. Opt., 44, 7218-7231, 2005.

Bordi, I., Fraedrich, K., Lunkeit, F., and Sutera, A.: Tropospheric double jets, meridional cells, and eddies: A case study and idealized simulations, Mon. Weather Rev., 135, 3118-3133, 2007.

Bordi, I., Fraedrich, K., and Sutera, A.: Multiple jets observed in the summer Northern Hemisphere troposphere, Nuovo Cimento Soc. Ital. Fis. C-Geophys. Space Phys., 30, 587-604, 2008.

Bosilovich, M. G., Schubert, S. D., Rienecker, M., Todling, R., Suarez, M., Bacmeister, J., Gelaro, R., Kim, G.-K., Stajner, I., and Chen, J.: NASA's Modern Era Retrospective-analysis for Research and Applications (MERRA), US CLIVAR Variations, 4 (2), 5-8, 2006.

Brioude, J., Cammas, J.-P., Cooper, O. R., and Nedelec, P.: Characterization of the composition, structure, and seasonal variation of the mixing layer above the extratropical tropopause as revealed by MOZAIC measurements, J. Geophys. Res., 113, D00B01, doi:10.1029/2007JD009184, 2008.

Butchart, N. and Scaife, A. A.: Removal of chlorofluorocarbons by increased mass exchange between the stratosphere and the troposphere in a changing climate, Nature, 410, 799-802, 2001. 
Coy, L., Eckermann, S., and Hoppel, K.: Planetary wave breaking and tropospheric forcing as seen in the stratospheric sudden warming of 2006, J. Atmos. Sci., 66, 495-507, 2009.

Duncan, B. N., Strahan, S. E., Yoshida, Y., Steenrod, S. D., and Livesey, N.: Model study of the cross-tropopause transport of biomass burning pollution, Atmos. Chem. Phys., 7, 3713-3736, doi:10.5194/acp-7-3713-2007, 2007.

Engel, A., Bönisch, H., Brunner, D., Fischer, H., Franke, H., Gnther, G., Gurk, C., Hegglin, M., Hoor, P., Knigstedt, R., Krebsbach, M., Maser, R., Parchatka, U., Peter, T., Schell, D., Schiller, C., Schmidt, U., Spelten, N., Szabo, T., Weers, U., Wernli, H., Wetter, T., and Wirth, V.: Highly resolved observations of trace gases in the lowermost stratosphere and upper troposphere from the Spurt project: an overview, Atmos. Chem. Phys., 6, 283-301, doi:10.5194/acp-6-283-2006, 2006.

Follette-Cook, M. B., Hudson, R. D., and Nedoluha, G. E.: Classification of Northern Hemisphere stratospheric ozone and water vapor profiles by meteorological regime, Atmos. Chem. Phys., 9, 5989-6003, doi:10.5194/acp-9-5989-2009, 2009.

Forster, P. M. F. and Shine, K. P.: Radiative forcing and temperature trends from stratospheric ozone changes, J. Geophys. Res., 102, 10841-10855, 1997.

Grise, K. M., Thompson, D. W. J., and Birner, T.: A global survey of static stability in the stratosphere and upper troposphere, J. Climate, 23, 2275-2292, 2010.

Hegglin, M. I. and Shepherd, T. G.: Large climate-induced changes in ultraviolet index and stratosphere-to-troposphere ozone flux, Nat. Geosci., 2, 687-691, 2009.

Hegglin, M. I., Brunner, D., Peter, T., Hoor, P., Fischer, H., Staehelin, J., Krebsbach, M., Schiller, C., Parchatka, U., and Weers, U.: Measurements of $\mathrm{NO}, \mathrm{NO}_{\mathrm{y}}, \mathrm{N}_{2} \mathrm{O}$, and $\mathrm{O}_{3}$ during SPURT: implications for transport and chemistry in the lowermost stratosphere, Atmos. Chem. Phys., 6, 1331-1350, doi:10.5194/acp-61331-2006, 2006.

Hegglin, M. I., Boone, C. D., Manney, G. L., Shepherd, T. G., Walker, K. A., Bernath, P. F., Daffer, W. H., Hoor, P., and Schiller, C.: Validation of ACE-FTS satellite data in the upper troposphere/lower stratosphere (UTLS) using noncoincident measurements, Atmos. Chem. Phys., 8, 1483-1499, doi:10.5194/acp-8-1483-2008, 2008.

Hegglin, M. I., Boone, C. D., Manney, G. L., and Walker, K. A.: A global view of the extratropical tropopause transition layer (ExTL) from Atmospheric Chemistry Experiment Fourier Transform Spectrometer $\mathrm{O}_{3}, \mathrm{H}_{2} \mathrm{O}$, and $\mathrm{CO}$, J. Geophys. Res., 114, D00B11, doi:10.1029/2008JD009984, 2009.

Highwood, E. J., Hoskins, B. J., and Berrisford, P.: Properties of the Arctic tropopause, Q. J. Roy. Meteor. Soc., 126, 1515-1532, 2000.

Hitchman, M. H. and Huesmann, A. S.: A seasonal climatology of Rossby wave breaking in the 320-2000-K layer, J. Atmos. Sci., 64, 1922-1940, 2007.

Holton, J. R., Haynes, P. H., McIntyre, M. E., Douglass, A. R., Rood, R. B., and Pfister, L.: Stratosphere-troposphere exchange, Rev. Geophys., 33, 403-439, 1995.

Homeyer, C., Bowman, K. P., and Pan, L. L.: Extratropical tropopause transition layer characteristics from highresolution sounding data, J. Geophys. Res., 115, D13108, doi:10.1029/2009JD013664, 2010.

Homeyer, C., Bowman, K. P., Pan, L. L., Atlas, E. L., Gao, R.-S., and Campos, T. L.: Dynamical and chemical characteristics of tropospheric intrusions observed during START08, J. Geophys. Res., 116, D06111, doi:10.1029/2010JD015098, 2011.

Hoor, P., Gurk, C., Brunner, D., Hegglin, M. I., Wernli, H., and Fischer, H.: Seasonality and extent of extratropical TST derived from in-situ CO measurements during SPURT, Atmos. Chem. Phys., 4, 1427-1442, doi:10.5194/acp-4-1427-2004, 2004.

Hsu, J. and Prather, M. J.: Stratospheric variability and tropospheric ozone, J. Geophys. Res., 114, D06102, doi:10.1029/2008JD010942, 2009.

Hudson, R. D., Frolov, A. D., Andrade, M. F., and Follette, M. B.: The total ozone field separated into meteorological regimes. Part I: Defining the Regimes, J. Atmos. Sci., 60, 1669-1677, 2003.

Isotta, F., Martius, O., Sprenger, M., and Schwierz, C.: Long-term trends of synoptic-scale breaking Rossby waves in the Northern Hemisphere between 1958 and 2001, Intl. J. Climatol., 28, 15511562, 2008.

Koch, P., Wernli, H., and Davies, H. C.: An event-based jet-stream climatology and typology, Int. J. Climatol., 26, 283-301, 2006.

Krebsbach, M., Schiller, C., Brunner, D., Gnther, G., Hegglin, M. I., Mottaghy, D., Riese, M., Spelten, N., and Wernli, H.: Seasonal cycles and variability of $\mathrm{O}_{3}$ and $\mathrm{H}_{2} \mathrm{O}$ in the UT/LMS during SPURT, Atmos. Chem. Phys., 6, 109-125, doi:10.5194/acp6-109-2006, 2006.

Kunz, A., Konopka, P., Müller, R., Pan, L. L., Schiller, C., and Rohrer, F.: High static stability in the mixing layer above the extratropical tropopause, J. Geophys. Res., 114, D16305, doi:10.1029/2009JD011840, 2009.

Kunz, A., Konopka, P., Müller, R., and Pan, L. L.: Dynamical tropopause based on isentropic potential vorticity gradients, J. Geophys. Res., 116, D01110, doi:10.1029/2010JD014343.

Lacis, A., Wuebbles, D. J., and Logan, J. A.: Radiative forcing of climate by changes in the vertical distribution of ozone, J. Geophys. Res., 95, 9971-9981, 1990.

Lee, A. M., Jones, R. L., Kilbane-Dawe, I., and Pyle, J. A.: Diagnosing ozone loss in the extratropical lower stratosphere, J. Geophys. Res., 107, D11, doi:10.1029/2001JD000538, 2002.

Levine, J. G., Braesicke, P., Harris, N. R. P., Savage, N. H., and Pyle, J. A.: Pathways and timescales for troposphere-tostratosphere transport via the tropical tropopause layer and their relevance for very short lived substances, J. Geophys. Res., 112, D04308, doi:10.1029/2005JD006940, 2007.

Livesey, N. J., Filipiak, M. J., Froidevaux, L., Read, W. G., Lambert, A., Santee, M. L., Jiang, J. H., Pumphrey, H. C., Waters, J. W., Cofield, R. E., Cuddy, D. T., Daffer, W. H., Drouin, B. J., Fuller, R. A., Jarnot, R. F., Jiang, Y. B., Knosp, B. W., Li, Q. B., Perun, V. S., Schwartz, M. J., Snyder, W. V., Stek, P. C., Thurstans, R. P., Wagner, P. A., Avery, M., Browell, E. V., Cammas, J.-P., Christensen, L. E., Diskin, G. S., Gao, R-S. , Jost, H-J., Loewenstein, M., Lopez, J. D., Nedelec, P., Osterman, G. B., Sachse, G. W., and Webster, C. R.: Validation of Aura Microwave Limb Sounder $\mathrm{O}_{3}$ and $\mathrm{CO}$ observations in the upper troposphere and lower stratosphere, J. Geophys. Res., 113, D15S02, doi:10.1029/2007JD008805, 2008.

Livesey, N. J., Read, W. G., Froidevaux, L., Lambert, A., Manney, G. L., Pumphrey, H. C., Santee, M. L., Schwartz, M. J., Wang, S., Cofield, ,R. E., Cuddy, D. T., Fuller, R. A., Jarnot, R. F., Jiang, J. H., Knosp, B. W., Stek, P. C., Wagner, P. A., and Wu, D. L.: Version 3.3 Level 2 data quality and description document, 
Tech. Rep. JPL D-33509, Jet Propulsion Laboratory, available at: http://mls.jpl.nasa.gov, 2011.

Lorenz, D. J. and DeWeaver, E. T.: Tropopause height and zonal wind response to global warming in the IPCC scenario integrations, J. Geophys. Res., 112, D10119, doi:10.1029/2006JD008087, 2007.

Manney, G. L., Santee, M. L., Froidevaux, L., Hoppel, K., Livesey, N. J., and Waters, J. W.: EOS MLS observations of ozone loss in the 2004-2005 Arctic winter, Geophys. Res. Lett., 33, L04802, doi:10.1029/2005GL024494, 2006.

Manney, G. L., Daffer, W. H., Zawodny, J. M., Bernath, P. F., Hoppel, K. W., Walker, K. A. , Knosp, B. W., Boone, C., Remsberg, E .E., Santee, M. L., Lynn Harvey, V., Pawson, S., Jackson, D. R., Deaver, L., McElroy, C. T., McLinden C. A., Drummond, J. R., Pumphrey, H. C., Lambert, A., Schwartz, M., J., Froidevaux, L., McLeod, S., Takacs, L. L., Suarez, M. J., Trepte, C. R., Cuddy, D. T., Livesey, N. J., Harwood, R. S., and Waters, J. W.: Solar occultation satellite data and derived meteorological products: Sampling issues and comparisons with Aura MLS, J. Geophys. Res., 112, D24S50, doi:10.1029/2007JD008709, 2007.

Manney, G. L., Schwartz, M. J., Krüger, K., Santee, M. L., Pawson, S., Lee, J. N., Daffer, W. H., Fuller, R. A., and Livesey, N. J.: Aura Microwave Limb Sounder observations of dynamics and transport during the record-breaking 2009 Arctic stratospheric major warming, Geophys. Res. Lett., 36, L12815, doi:10.1029/2009GL038586, 2009a.

Manney, G. L., Harwood, R. S., MacKenzie, I. A., Minschwaner, K., Allen, D. R., Santee, M. L., Walker, K. A., Hegglin, M. I., Lambert, A., Pumphrey, H. C., Bernath, P. F., Boone, C. D., Schwartz, M. J., Livesey, N. J., Daffer, W. H., and Fuller, R. A.: Satellite observations and modeling of transport in the upper troposphere through the lower mesosphere during the 2006 major stratospheric sudden warming, Atmos. Chem. Phys., 9, 47754795, doi:10.5194/acp-9-4775-2009, 2009b.

Manney, G. L., Hegglin, M. I., Daffer, W. H., Pawson, S., and Schwartz, M. J.: Climatology and variability of upper tropospheric/lower stratospheric jets from MERRA reanalyses, J. Climate, in preparation, 2011.

Martius, O., Polvani, L. M., and Davies, H. C.: Blocking precursors to stratospheric sudden warming events, Geophys. Res. Lett., 36, L14806, doi:10.1029/2009GL038776, 2009.

McLandress, C. and Shepherd, T. G.: Simulated anthropogenic changes in the Brewer-Dobson circulation, including its extension to high latitudes, J. Climate, 22, 1516-1540, 2009.

Miyazaki, K., Watanabe, S., Kawatani, Y., Tomikawa, Y., Takahashi, M., and Sato, K.: Transport and mixing in the extratropical tropopause region in a high-vertical-resolution GCM. Part I: Potential vorticity and heat budget analysis, J. Atmos. Sci., 67, 1293-1314, 2010a.

Miyazaki, K., Watanabe, S., Kawatani, Y., Tomikawa, Y., Takahashi, M., and Sato, K.: Transport and mixing in the extratropical tropopause region in a high-vertical-resolution GCM. Part II: Relative importance of large-scale and small-scale dynamics, J. Atmos. Sci., 67, 1315-1336, 2010b.

Ordóñez, C., Brunner, D., Staehelin, J., Hadjinicolaou, P., Pyle, J. A., Jonas, M., Wernli, H., and Prévôt, A. S. H.: Strong influence of lowermost stratospheric ozone on lower tropospheric background ozone changes over Europe, Geophys. Res. Lett., 34, L07805, doi:10.1029/2006GL029113, 2007.
Pan, L. L., Randel, W. J., Gary, B. L., Mahoney, M. J., and Hintsa, E. J.: Definitions and sharpness of the extratropical tropopause: A trace gas perspective, J. Geophys. Res., 109, D23103, doi:10.1029/2004JD004982, 2004.

Pan, L. L., Randel, W. J., Gille, J. C., Hall, W. D., Nardi, B., Massie, S., Yudin, V., Khosravi, R., Konopka, P., and Tarasick, D.: Tropospheric intrusions associated with the secondary tropopause, J. Geophys. Res., 114, D10302, doi:10.1029/2008JD011374, 2009.

Pan, L. L., Powman, K. P., Atlas, E. L., Pan, L. L., Bowman, K. P., Atlas, E. L., Wofsy, S. C., Zhang, F., Bresch, J. F., Ridley, B. A., Pittman, J. V., Homeyer, C. R., Romashkin, P., and Cooper, W. A.: The Stratosphere-Troposphere Analysis of Regional Transport 2008 Experiment, B. Am. Meteorol. Soc., 91, 327-342, 2010.

Proffitt, M. H. and McLaughlin, R. J.: Fast-response dual-beam UV absorption ozone photometer suitable for use in stratospheric balloons, Rev. Sci. Instrum., 54, 1719-1728, 1983.

Randel, W. J. and Held, I. M.: Phase speed spectra of transient eddy fluxes and critical layer absorption, J. Atmos. Sci., 48, 688-697, 1991.

Randel, W. J., Park, M., and Wu, F.: A Large Annual Cycle in Ozone above the Tropical Tropopause Linked to the BrewerDobson Circulation, J. Atmos. Sci., 64, 4479-4488, 2007a.

Randel, W. J., Seidel, D. J., and Pan, L.: Observational characteristics of double tropopauses, J. Geophys. Res., 112, D07309, doi:10.1029/2006JD00794, 2007b.

Randel, W. J., Wu, F., and Forster, P.: The extratropical inversion layer: global observations with GPS data, and a radiative forcing mechanism, J. Atmos. Sci., 64, 4489-4496, 2007c.

Ray, E. A., Rosenlof, K. H., Richard, E., Parrish, D., and Jakoubek, R.: Distributions of ozone in the region of the subtropical jet: An analysis of in situ aircraft measurments, J. Geophys. Res., 109, D08106, doi:10.1029/2003JD004143, 2004.

Reinecker, M. M., Suarez, M. J., Todling, R., Bacmeister, J., Takacs, L., Liu, H.-C., Gu, W., Sienkiewicz, M., Koster, R. D., Gelaro, R., Stajner, I., and Nielsen, E.: The GEOS-5 Data Assimilation System: A Documentation of GEOS-5.0, Tech. Rep. 104606 V27, NASA, 2008.

Reinecker, M. M., Suarez, M. J., Gelaro, R., Todling, R., Bacmeister, J., Liu, E., Bosilovich, M. G., Schubert, S. D., Takacs, L., Kim, G.-K., Bloom, S., Chen, J., Collins, D., Conaty, A., da Silva, A., Gu, W., Joiner, J., Koster, R. D., Lucchesi, R., Molod, A., Owens, T., Pawson, S., Pegion, P., Redder, C. R., Reichle, R., Robertson, F. R., Ruddick, A. G., Sienkiewicz, M., and Woollen, J.: MERRA - NASA's Modern-Era Retrospective Analysis for Research and Applications, J. Climate, doi:10.1175/JCLI-D-1100015.1, in press, 2011.

Rosenlof, K. H., Tuck, A. F., Kelly, K., Russell, J. M., and McCormick, M. P.: Hemispheric asymmetries in water vapor and inferences about transport in the lower stratosphere, J. Geophys. Res., 102, 13213-213234, 1997.

Sajda, P., Pohlmeyer, E., Wang, J., Parra, L. C., Christoforou, C., Dmochowski, J., Hanna, B., Bahlmann, C., Singh, M. K., and Chang, S.-F.: In a blink of an eye and a switch of a transistor: Cortically Coupled Computer Vision, Proceed. IEEE, 98, 462478, 2010.

Santee, M. L., Manney, G. L., Froidevaux, L., Livesey, N. J., Read, W. G., and Schwartz, M. J.: Trace gas evolution in the lowermost stratosphere from Aura Microwave Limb Sounder measure- 
ments: Subvortex processing and transport, J. Geophys. Res., in press, 2011.

Schiemann, R., Lüthi, D., and Schar, C.: Seasonality and interannual variability of the westerly jet in the Tibetan Plateau region, J. Climate, 22, 2940-2957, 2009.

Schoeberl, M. R.: Extratropical stratosphere-troposphere mass exchange, J. Geophys. Res., 109, D13303, doi:10.1029/2004JD004525, 2004.

Seidel, D. J., Fu, Q., Randel, W. J., and Reichler, T. J.: Widening of the tropical belt in a changing climate, Nat. Geosci., 1, 21-24, 2008.

Shepherd, T. G.: Dynamics, Stratospheric Ozone, and Climate Change, Atmos.-Ocean, 46, 371-392, 2008.

Shine, K. P., Bourqui, M. S., de Forster, P. M., Hare, S. H. E., Langematz, U., Braesicke, P., Grewe, V., Ponater, M., Schnadt, C., Smith, C. A., Haigh, J. D., Austin, J., Butchart, N., Shindell, D. T., Randel, W. J., Nagashima, T., Portmann, R. W., Solomon, S., Seidel, D. J., Lanzante, J., Klein, S., Ramaswamy, V., and Schwarzkopf, M. D.: A comparison of model-simulated trends in stratospheric temperatures, Q. J. Roy. Meteor. Soc., 129, 15651588, 2003.

Sigmond, M. and Scinocca, J. F.: The influence of the basic state on the northern hemisphere circulation response to climate change, J. Climate, 23, 1434-1446, 2010.

Solomon, S., Rosenlof, K. H., Portmann, R. W., Daniel, J. S., Davis, S. M., Sanford, T. J., and Plattner, G.-K.: Contributions of stratospheric water vapor to decadal changes in the rate of global warming, Science, 327, 1219-1223, 2010.

Son, S.-W., Polvani, L. M., Waugh, D. W., Akiyoshi, H., Garcia, R., Kinnison, D., Pawson, S., Rozanov, E., Shepherd, T. G., and Shibata, K.: The Impact of Stratospheric Ozone Recovery on the Southern Hemisphere Westerly Jet, Science, 320, 1486-1489, 2008.

Strong, C. and Davis, R. E.: Winter jet stream trends over the Northern Hemisphere, Q. J. Roy. Meteor. Soc., 133, 2109-2115, 2007.

Strong, C. and Davis, R. E.: Variability in the position and strength of winter jet stream cores related to Northern Hemisphere Teleconnections, J. Climate, 21, 584-592, 2008a.

Strong, C. and Davis, R. E.: Comment on "Historical trends in the jet streams" by Cristina L. Archer and Ken Caldeira, Geophys. Res. Lett., 35, L24806, doiL10.1029/2008GL034829, 2008 b.
Szunyogh, I., Toth, Z., Zimin, A. V., Majundar, S. J., and Persson, A.: Propagation of the effect of targeted observations: The 2000 Winter Storm Reconnaissance Program, Mon. Weather Rev., 130, 1144-1165, 2002.

Terao, Y., Logan, J. A., Douglas, A. R., and Stolarski, R. S.: Contribution of stratospheric ozone to the interannual variability of tropospheric ozone in the northern extratropics, J. Geophys. Res., 113, D18309, doi:10.1029/2008JD009854, 2008.

Tilmes, S., Pan, L. L., Hoor, P., Atlas, E., Avery, M. A., Campos, T., Christensen, L. E., Diskin, G. S., Gao, R. S., Herman, R. L., Hintsa, E. J., Loewenstein, M., Lopez, J., Paige, M. E., Pittman, J. V., Podolske, J. R., Proffitt, M. R., Sachse, G. W., Schiller, C., Schlager, H., Smith, J., Spelten, N., Webster, C., Weinheimer, A., and Zondlo, M. A.: J. Geophys. Res., 115, D14303, doi:10.1029/2009JD012731, 2010

von Ahn, L., Maurer, B., McMillen, C., Abraham, D., and Blum, M.: reCAPTCHA: Human-based character recognition via web security measures, Science, 321, 1465-1468, 2008.

Waters, J. W., Froidevaux, L., Harwood, R. S., Jarnot, R. F., Pickett, H. M., Read, W. G., Siegel, P. H., Cofield, R. E., Filipiak, M. J., Flower, D. A., Holden, J. R., Lau, G. K., Livesey, N. J., Manney, G. L., Pumphrey, H. C., Santee, M. L., Wu, D. L., Cuddy, D. T., Lay, R. R., Loo, M. S., Perun, V. S., Schwartz, M. J., Stek, P. C., Thurstans, R. P., Boyles, M. A., Chandra, S., Chavez, M. C., Chen, G.-S., Chudasama, B. V., Dodge, R., Fuller, R. A., Girard, M. A., Jiang, J. H., Jiang, Y., Knosp, B. W., LaBelle, R. C., Lam, J. C., Lee, K. A., Miller, D., Oswald, J. E., Patel, N. C., Pukala, D. M., Quintero, O., Scaff, D. M., Snyder, W. V., Tope, M. C., Wagner, P. A., and Walch, M. J.: The Earth Observing System Microwave Limb Sounder (EOS MLS) on the Aura satellite, IEEE T. Geosci. Remote, 44, 1075-1092, 2006.

Waugh, D. W. and Polvani, L. M.: Climatology of intrusions into the tropical upper troposphere, Geophys. Res. Lett., 27, 38573860, 2000.

World Meteorological Organization: Scientific assessment of ozone depletion: 2006, Global Ozone Res. and Monit. Proj. Rep. 50, Geneva, Switzerland, 2007.

Wu, W.-S., Purser, R. J., and Parish, D. F.: Three-dimensional variational analyses with spatially inhomogeneous covariances, Mon. Weather Rev., 130, 2905-2916, 2002. 